\title{
Intercomparison of biomass burning aerosol optical properties from in situ and remote-sensing instruments in ORACLES-2016
}

\author{
Kristina Pistone ${ }^{1,2}$, Jens Redemann ${ }^{3}$, Sarah Doherty ${ }^{4}$, Paquita Zuidema ${ }^{5}$, Sharon Burton ${ }^{6}$, Brian Cairns ${ }^{7}$, \\ Samuel LeBlanc $^{1,2}$, Xu Liu ${ }^{6}$, K. Sebastian Schmidt ${ }^{8}$, Arthur J. Sedlacek III ${ }^{11}$, Michal Segal-Rozenhaimer ${ }^{1,2}$, \\ Yohei Shinozuka $^{12,2}$, Snorre Stamnes ${ }^{6}$, Bastiaan van Diedenhoven ${ }^{13,7}$, Gerard Van Harten ${ }^{14}$, and Feng Xu${ }^{14}$ \\ ${ }^{1}$ Bay Area Environmental Research Institute, Moffett Field, CA, USA \\ ${ }^{2}$ NASA Ames Research Center, Moffett Field, CA, USA \\ ${ }^{3}$ School of Meteorology, University of Oklahoma, Norman, OK, USA \\ ${ }^{4}$ JISAO, University of Washington, Seattle, WA, USA \\ ${ }^{5}$ University of Miami/Rosenstiel School of Marine and Atmospheric Science, Miami, FL, USA \\ ${ }^{6}$ NASA Langley Research Center, Hampton, VA, USA \\ ${ }^{7}$ NASA Goddard Institute for Space Studies, New York, NY, USA \\ ${ }^{8}$ University of Colorado, Boulder, CO, USA \\ ${ }^{9}$ Pacific Northwest National Laboratory, Richland, WA, USA \\ ${ }^{10}$ University of Hawaii at Manoa, Honolulu, HI, USA \\ ${ }^{11}$ Brookhaven National Laboratory, Brookhaven, NY, USA \\ ${ }^{12}$ Universities Space Research Association, Mountain View, CA, USA \\ ${ }^{13}$ Columbia University, Center for Climate System Research, New York, NY, USA \\ ${ }^{14}$ Jet Propulsion Laboratory, California Institute of Technology, Pasadena, CA, USA
} Sabrina Cochrane $^{8}$, Richard Ferrare ${ }^{6}$, Connor Flynn ${ }^{9}$, Steffen Freitag ${ }^{10}$, Steven G. Howell ${ }^{10}$, Meloë Kacenelenbogen ${ }^{2}$,

Correspondence: Kristina Pistone (kristina.pistone@nasa.gov)

Received: 15 February 2019 - Discussion started: 20 February 2019

Revised: 8 June 2019 - Accepted: 11 June 2019 - Published: 18 July 2019

\begin{abstract}
The total effect of aerosols, both directly and on cloud properties, remains the biggest source of uncertainty in anthropogenic radiative forcing on the climate. Correct characterization of intensive aerosol optical properties, particularly in conditions where absorbing aerosol is present, is a crucial factor in quantifying these effects. The southeast Atlantic Ocean (SEA), with seasonal biomass burning smoke plumes overlying and mixing with a persistent stratocumulus cloud deck, offers an excellent natural laboratory to make the observations necessary to understand the complexities of aerosol-cloud-radiation interactions. The first field deployment of the NASA ORACLES (ObseRvations of Aerosols above CLouds and their intEractionS) campaign was conducted in September of 2016 out of Walvis Bay, Namibia.

Data collected during ORACLES-2016 are used to derive aerosol properties from an unprecedented number of simultaneous measurement techniques over this region. Here, we
\end{abstract}

present results from six of the eight independent instruments or instrument combinations, all applied to measure or retrieve aerosol absorption and single-scattering albedo. Most but not all of the biomass burning aerosol was located in the free troposphere, in relative humidities typically ranging up to $60 \%$. We present the single-scattering albedo (SSA), absorbing and total aerosol optical depth (AAOD and AOD), and absorption, scattering, and extinction Ångström exponents (AAE, SAE, and EAE, respectively) for specific case studies looking at near-coincident and near-colocated measurements from multiple instruments, and SSAs for the broader campaign average over the month-long deployment. For the case studies, we find that SSA agrees within the measurement uncertainties between multiple instruments, though, over all cases, there is no strong correlation between values reported by one instrument and another. We also find that agreement 
between the instruments is more robust at higher aerosol loading $\left(\mathrm{AOD}_{400}>0.4\right)$.

The campaign-wide average and range shows differences in the values measured by each instrument. We find the ORACLES-2016 campaign-average SSA at $500 \mathrm{~nm}$ ( $\mathrm{SSA}_{500}$ ) to be between 0.85 and 0.88 , depending on the instrument considered (4STAR, AirMSPI, or in situ measurements), with the interquartile ranges for all instruments between 0.83 and 0.89 . This is consistent with previous September values reported over the region (between 0.84 and 0.90 for SSA at $550 \mathrm{~nm}$ ). The results suggest that the differences observed in the campaign-average values may be dominated by instrument-specific spatial sampling differences and the natural physical variability in aerosol conditions over the SEA, rather than fundamental methodological differences.

\section{Introduction}

Atmospheric aerosols are an important component of the climate system in terms of their direct, semi-direct, and indirect radiative effects. A primary factor governing the overall magnitude of these effects is the composition, size, mixing state, and concentration (and, consequently, the radiative properties) of the aerosol in a given location. While, on the global average, aerosols predominantly cool the planet by reflecting sunlight back to space, shortwave-absorbing aerosols (such as those from biomass burning sources) are also capable of warming the planet by directly absorbing sunlight (called the direct effect: Chylek and Coakley, 1974; Meyer et al., 2015; Zhang et al., 2016). Aerosols can additionally affect cloud properties by microphysical indirect effects affecting droplet size and lifetime (e.g., Twomey, 1974; Albrecht, 1989; McComiskey and Feingold, 2012; Lu et al., 2018); by altering surface evaporation, cloud burn-off rates, and atmospheric dynamics, the so-called semi-direct aerosol effects (e.g., Ackerman et al., 2000; Koch and Del Genio, 2010; Wilcox, 2010; Sakaeda et al., 2011; Wilcox, 2012; Gordon et al., 2018); or by some combination of the above (e.g., Adebiyi and Zuidema, 2018; Brown et al., 2018).

In this work, we focus on the aerosol single-scattering albedo (SSA), the ratio of aerosol scattering to total extinction. SSA is a key intensive property which relates to the aerosol composition while being independent of the total aerosol loading. Weakly absorbing or non-absorbing particles such as sea salt will have SSA close to 1 , whereas biomass burning (BB) smoke made up of more highly absorbing soot particles will have SSA less than 1 . These BB SSAs are typically observed to be between 0.7 and 0.95 (e.g., Dubovik et al., 2002; Eck et al., 2013; Sayer et al., 2014), though laboratory studies show these values can be much lower under conditions of high modified combustion efficiencies and low organic (versus black carbon) mass frac- tion (i.e., higher BC content) (e.g., Liu et al., 2014; Vakkari et al., 2014; Pokhrel et al., 2016). Column-average SSA, as discussed here, may be composed of contributions from several different aerosol types. SSA, among other parameters, is essential for the determination of direct aerosol radiative effects. SSA has been shown to evolve with BB plume location, age, mixing state, emission source, and distance from source (e.g., Haywood et al., 2003; Eck et al., 2013; Konovalov et al., 2017).

Other important parameters are the aerosol optical depth (AOD) and the absorbing component of AOD (AAOD, defined as AOD · (1 - SSA)), which indicate the magnitude of the column (absorbing) aerosol loading. In the present work, AODs from the different retrievals are presented to assess the similarity between temporally and spatially dislocated scenes observed by the different instruments, and since the retrievals of AOD and SSA are not necessarily uncoupled, AOD can be a useful diagnostic. However, as we focus here on intensive aerosol properties, the climatological AOD values are not discussed. Finally, we discuss the Ångström exponents from each retrieval method (AAE, SAE, and EAE for the absorption, scattering, and extinction Ångström exponents, respectively). Angström exponents are given by the log-space slope of absorption, scattering, or extinction aerosol optical depths versus wavelength, and are frequently used to characterize atmospheric aerosol. As AAE is primarily (though not entirely) determined by aerosol composition (Russell et al., 2010; Bahadur et al., 2012) and SAE is primarily associated with aerosol size, these parameters can be instructive in understanding the nature of the aerosol in question. EAE is shown as well, to place these results in the context of other remote-sensing results which measure extinction, though EAE closely follows SAE since extinction is dominated by scattering for almost all atmospheric aerosols. Accurate representation of the magnitude and variability of these aerosol properties on a regional scale has significant implications for aerosol radiative effects calculated using climate models and/or satellite data. As different instruments (such as those incorporated into this work) may rely on different physical measurement principles, each with different considerations and limitations (Table 1), an understanding of how distinct observations compare to one another is a critical piece in gaining an understanding of our observational limitations for key parameters and hence in calculating aerosol effects and their uncertainties.

This paper presents data from the NASA ORACLES (ObseRvations of Aerosols above CLouds and their intEractionS) campaign (Zuidema et al., 2016), a multi-year, multiplatform collaboration to sample clouds and BB aerosol over the southeast Atlantic Ocean (SEA). During the 2016 ORACLES deployment, two NASA aircraft (a P-3 and an ER-2) were flown with a suite of aerosol, cloud, radiation, and meteorological instruments for remote-sensing and in situ observations. The remainder of this section gives a brief context of previous observations over this region (Sect. 1.1), their impli- 
cations (Sect. 1.2) and an overview of the ORACLES campaign (Sect. 1.3). Section 2 describes data and methods used, including the ORACLES instrumentation, flight paths, and comparison case criteria. Section 3.1 details two case studies of the multi-instrument comparisons (in situ and remotesensing instruments), and Sect. 3.2 presents campaign-wide comparisons of in situ versus remote-sensing measurements. Finally, in Sect. 4, we describe the broader picture of the average aerosol properties measured over the region during ORACLES-2016 and discuss how these results fit within the context of previous observations. Additional considerations of the in situ data are provided in Appendix A.

\subsection{SEA aerosol climatology}

The SEA is a particularly important region in the context of understanding aerosol-radiation and aerosol-cloud interactions. This region exhibits a persistent stratocumulus cloud deck off the western coast of Africa. During the southern African biomass burning season (August to October), these clouds are situated under and/or within plumes of absorbing aerosols originating from widespread continental fires. The smoke is lofted in continental convection and then advected westward in the southerly branch of the African easterly jet at a typical altitude of 3-5 km in September (Adebiyi and Zuidema, 2016), which approximately coincides with the observed plume altitude over the region. The composition of these aerosols (as reflected in the SSA parameter) can change the magnitude and even the sign of the radiative forcing effects of aerosol over clouds (e.g., Chand et al., 2009; Zuidema et al., 2016; Cochrane et al., 2019; Kacenelenbogen et al., 2019).

Compared with other regions of the world, there have been relatively few studies measuring aerosol properties (microphysical or radiative) either directly over the southeast Atlantic or near their source in Sub-Saharan Africa. Nonetheless, there is still a good deal of previous work which can help to place the ORACLES observations in context. A key observational dataset is from the Southern African Regional Science Initiative (SAFARI-2000) campaign which used aircraft to measure aerosol properties over and in close proximity to the coast of southern Africa in September 2000, including both aged aerosol and fresh biomass plumes (e.g., Haywood et al., 2003; Schmid et al., 2003; Leahy et al., 2007; Russell et al., 2010). SAFARI-2000 also resulted in the establishment of several sites of the AErosol RObotic NETwork (AERONET) on the African continent; these allow for longer-term climatological analysis near emission sources (e.g., Quéfacé et al., 2003; Magi and Hobbs, 2003; Swap et al., 2003; Eck et al., 2003, 2013). Passive and active satellite observations have also been used to detect and quantify aerosol above clouds over the SEA region (e.g., Chand et al., 2008, 2009; Waquet et al., 2013; Jethva et al., 2014; Torres et al., 2012; Liu et al., 2015), though such studies typically need to assume (through lookup tables or models) cloud and aerosol properties as well as their relative geometry. In this context, the ORACLES aircraft-based dataset, designed to sample the region of highest cloud cover and BB smoke concentration, provides important and heretofore unique observations of both aerosol and clouds over the southeast Atlantic Ocean, due to both improved instrumentation since SAFARI2000 and because ORACLES focused on regions farther off the southern African coast than previously measured.

The previous studies give a somewhat limited yet still useful view of the temporal and seasonal trends in SSA for a limited set of locations within this region (Fig. 1). In the SAFARI-2000 campaign, aircraft instrumentation was used to sample both the aged aerosol plume (a few days old) and fresh biomass aerosol (a few minutes old) over Namibia and the coastal SEA. The mean SSA of the aged haze was reported by Haywood et al. (2003) as 0.91, 0.90, and 0.87 at 450,550 , and $700 \mathrm{~nm}$ using a combination of an in situ aircraft-based Particle Soot Absorption Photometer (PSAP) and nephelometer. However, Leahy et al. (2007) reported a lower "best estimate" (campaign-average) $\mathrm{SSA}_{550 \mathrm{~nm}}$ of $0.85 \pm 0.02$ using the SAFARI airborne flux radiometry and in situ measurements combined with groundbased AERONET retrievals; the individual flux radiometry estimate is described in Bergstrom et al. (2003) and Russell et al. (2010) and included separately in Fig. 1. For a SAFARI flight specifically targeting fresh biomass burning smoke, the reported SSA was lower, at $0.86,0.84$, and 0.80 (Haywood et al., 2003). Thus, even within a single campaign, past work has shown a sizable range in BB aerosol properties. It should be noted that the SAFARI over-ocean flights were conducted within a more southern region (generally $15-25^{\circ} \mathrm{S}$ ) than the heart of the seasonal aerosol plume typically described as extending approximately $0-15^{\circ} \mathrm{S}$ (Zuidema et al., 2016). The ORACLES sampling area spans both these latitude ranges $\left(0-25^{\circ} \mathrm{S}\right)$ but frequently sampled westward of the SAFARI region. SAFARI also made many measurements over the continent, closer to biomass burning sources, whereas the ORACLES measurements were made entirely over the ocean. It is therefore likely that the SAFARI measurements were of generally younger aerosol than the ORACLES measurements, including the aerosol identified as "aged" within Haywood et al. (2003).

An AERONET-based climatology by Dubovik et al. (2002) indicated that the African BB site (Zambia, $15^{\circ} 15^{\prime} \mathrm{S}$, $23^{\circ} 09^{\prime} \mathrm{E}$ ) had the lowest SSA (i.e., strongest absorption) and the strongest SSA spectral dependence (i.e., steepest slope, $\mathrm{SSA}_{440 \mathrm{~nm}}=0.88$ to $\mathrm{SSA}_{1020 \mathrm{~nm}}=0.78$ ) among the four geographical $\mathrm{BB}$ regions considered. This was attributed to the greater flaming versus smoldering characteristics of these fires compared with other regions. Using data from the same long-term AERONET site at Mongu, Zambia, Eck et al. (2013) found a seasonal progression of increasing full-column SSA (decreasing relative absorption) over the July-to-November burning season based on data from 1997 to 2005 . SSA increased from $\mathrm{SSA}_{440 \mathrm{~nm}}=0.84$ in July 
to $\mathrm{SSA}_{440 \mathrm{~nm}}=0.93$ in November (Fig. 1). This same pattern was observed in a study of near-surface in situ SSA measurements at Ascension Island, showing monthly mean $\mathrm{SSA}_{529 \mathrm{~nm}}$ increasing from 0.78 in August 2016 to 0.83 in October 2016 (Zuidema et al., 2018). We note this site is substantially westward (downwind) of the majority of ORACLES flights and thus may represent more aged aerosol. Eck et al. (2013) also reported an average September SSA similar to that reported by Dubovik et al. (2002) for Zambia: 0.88, $0.83,0.81$, and 0.79 at $440,675,870$, and $1020 \mathrm{~nm}$, respectively. They also showed that within a given month, a southto-north increase in $\mathrm{SSA}_{388}$ is observed, as derived from the satellite-based OMI (Ozone Monitoring Instrument) retrievals. This was hypothesized to be due to shifts in fuel type over the BB season due to both anthropogenic factors (i.e., timing/practices of agricultural burning) and environmental factors (i.e., relating to moisture variability of potential fuel types throughout the season). Variations in atmospheric humidity have also been shown to affect aerosol optical properties, including both aerosol scattering and absorption (e.g., Langridge et al., 2011; Lack and Cappa, 2010). Figure 1 summarizes the previous work in this region and indicates that the SSA over southern Africa increases through the burning season (monthly averages from Eck et al., 2013), possibly due to changes in biomass burning fuel composition, and also that SSA may increase with distance from fire, i.e., as the aerosol ages (fresh versus aged plume of Haywood et al., 2003). However, we emphasize that the "aging" timescales observed in SAFARI-2000 were much shorter (e.g., $\sim 5 \mathrm{~h}$ in Abel et al. (2003); within a few days in Haywood et al., 2003) than those seen in ORACLES ( 2-15 d, e.g., Dobracki et al., 2019). This may account for the opposite sign (higher SSA for younger aerosol) shown in the latter work. Thus, it is clear that multiple physical factors may be responsible for variability in aerosol optical properties.

Further discussion of previous studies of SEA aerosol in the context of the ORACLES results is found in Sect. 4.

\subsection{Impacts of SSA on aerosol radiative effects}

Accurate representation of scattering versus absorption within biomass burning aerosol scenes has implications in subsequent calculations of aerosol radiative effects over the SEA. The range of SSA values shown in Fig. 1 encompasses the possibility of both positive (smaller values of SSA) or negative (higher values of SSA) net direct radiative effect when this aerosol is above the partly cloudy skies of the SEA. The specific value of SSA where the radiative effect changes sign will depend on the cloud cover fraction; for example, in Chand et al. (2009), the aerosol direct effect was positive for a mid-visible SSA of 0.85 as long as cloud fraction was greater than $40 \%$. Wilcox (2012) found that for a perturbation to SSA of \pm 0.03 , the local direct aerosol radiative effect was changed by $10-20 \mathrm{~W} \mathrm{~m}^{-2}$, though this also depends on AOD and cloud albedo conditions. A perturba-

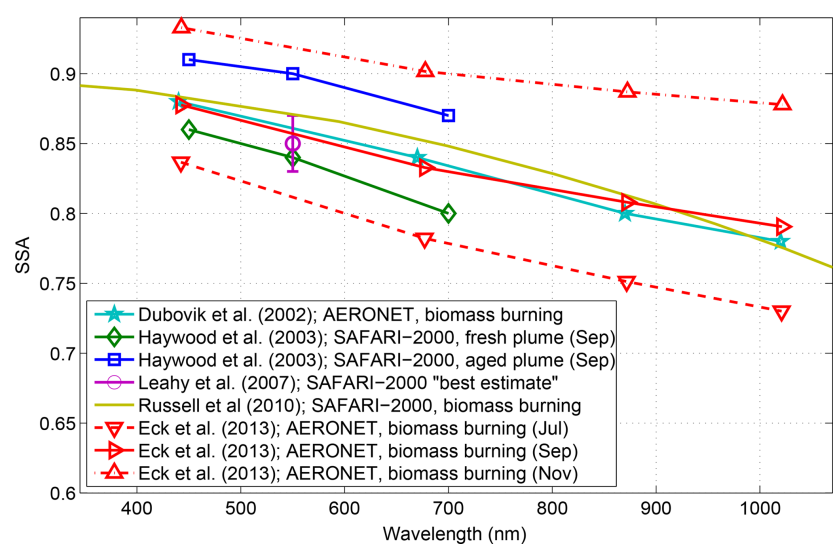

Figure 1. Summary of average SEA/African BB SSA as reported in previous studies as described in the text. The spatial and methodological variability can be noted from the Haywood et al. (2003) versus Russell et al. (2010) SAFARI-2000 results, and the seasonal changes in SSA are seen in the Eck et al. (2013) monthly averages from the Zambian AERONET site.

tion of this magnitude encompasses only half the range between the lowest and highest September SSA values shown in Fig. 1. As described above, some of this range may reflect seasonal variations in SSA, but even for September alone, the previously measured values of SSA $550 \mathrm{~nm}$ spanned $0.84-0.90$. An open question is to what degree the range in previous observations represents real variability in the SSA of smoke in this region or whether a significant part of the range is due to differences in measurement techniques and in measurement conditions; for example, the AERONET and flux radiometry retrievals are for ambient relative humidity $(\mathrm{RH})$ aerosol, whereas the in situ (SAFARI) measurements are of dry/low$\mathrm{RH}$ aerosol. We endeavor to explore these questions in the following sections.

\subsection{ORACLES overview}

The overarching goal of ORACLES is to make high-quality airborne observations of aerosols and clouds in the SEA to gain a better understanding of the complex processes (direct, indirect, and semi-direct) by which BB aerosols, notable for their strong absorption of solar energy, affect radiation both directly and through their impacts on clouds (Zuidema et al., 2016). The project included three field deployments of approximately 1 month each: September 2016 based out of Walvis Bay, Namibia; August 2017 based out of São Tomé, São Tomé and Príncipe; and October 2018 again based out of São Tomé. The ORACLES study area time zone spans UTC and UTC +1 . In the current paper, we focus on the first field deployment of ORACLES in September of 2016 out of Walvis Bay, Namibia. This deployment included two NASA aircraft: a P-3 for full atmospheric profiling and low-/mid-level in situ sampling, and a high-altitude ER-2 for remote-sensing observations. The P-3 aircraft was flown with 
a suite of in situ and remote-sensing aerosol, cloud, radiation, and meteorological instruments, while the ER-2 carried only remote-sensing instrumentation. Data were collected over 15 P-3 and 12 ER-2 flights, each 7-9 $\mathrm{h}$ in duration. The 2017 and 2018 deployments included the P-3 only. Hence, the simultaneous deployment of both the P-3 and the ER-2 in the 2016 deployment created a unique testbed for evaluating remotesensing retrievals of aerosol and cloud properties from a variety of instruments that have potential for future space flight.

Of the in situ and remote-sensing instruments included in ORACLES, eight teams (including the complementary AERONET sites, several of which were established to coordinate with the ORACLES deployments) observe or derive aerosol absorption (either locally or as column AAOD) and the related SSA parameter (Table 1). All considered remote-sensing instruments report an AOD product, with the exception of the Solar Spectral Flux Radiometer (SSFR), which uses AODs from the Spectrometers for Sky-Scanning Sun-Tracking Atmospheric Research (4STAR) as input (each of these instruments is described below). Remote-sensing SSAs are reported as column-integrated values; for in situ measurements, the SSA presented is the extinction-weighted profile-average value (i.e., SSA calculated at each altitude and weighted by the profile of extinction; Sect. 2.1.3). Unless otherwise noted, reported Ångström exponents (AEs) are calculated using a logarithmic fit of the AOD versus wavelength using all available wavelengths between 440 and $675 \mathrm{~nm}$ (inclusive), to have the most comparable quantity between instruments and to reduce uncertainty compared with a simple two-wavelength calculation of the AE. While previous studies have examined the agreement between the retrievals of a few of these instruments at a time (e.g., Sedlacek and Lee, 2007; Leahy et al., 2007; Knobelspiesse et al., 2011), an intercomparison including so many methods within one campaign has not previously been performed, due to the logistics of assembling such a comprehensive suite of instruments including several newly developed algorithms. Specific instrument details are given in the following section. A more detailed overview of the campaign design and goals may be found in Zuidema et al. (2016), and an overview of the results will be the focus of a future paper.

\section{Methods}

\subsection{Instruments and data}

In this section, we offer descriptions of the instruments and data included in this paper, as summarized in Table 1.

\subsubsection{STAR}

4STAR is an airborne hyperspectral $(350-1700 \mathrm{~nm})$ Sun photometer which can make direct-beam (Sun-tracking mode) measurements for retrieval of column AOD and trace gases (Dunagan et al., 2013; Shinozuka et al., 2013; Segal-
Rosenheimer et al., 2014) or below-cloud measurements of transmittance for derivation of cloud optical properties (zenith mode). Under certain level-flying conditions, 4STAR can also perform AERONET-like sky scans in either the principal plane or almucantar (sky-scanning mode), which provide the data used here. The 4STAR sky scans are processed using a modified version of the version 2 AERONET retrieval algorithm described in Dubovik and King (2000), which retrieves aerosol size distributions, refractive indices, SSA, and AAOD, among other parameters. All scans are run through the algorithm with the minimum scattering angle set to $3^{\circ}$ to avoid stray light from the Sun entering the 4STAR optical aperture. Scene (i.e., surface plus atmosphere) albedo is provided by SSFR measurements (described below). A notable modification of the 4STAR retrievals compared with AERONET retrievals is in the input wavelengths. While AERONET uses radiances measured at specific and discrete wavelengths $(440,675,870$, and $1020 \mathrm{~nm})$, with the hyperspectral 4STAR we are able to use AODs and sky radiances measured at a different (or larger) selection of wavelengths. Due to suspected stray light contamination within the 4STAR spectrometer around $440 \mathrm{~nm}$, a particular sensitivity to the $440 \mathrm{~nm}$ channel was observed, which in some cases resulted in an anomalously low SSA (high AAOD) at shorter wavelengths compared with retrievals run without $440 \mathrm{~nm}$. To avoid this issue, the results presented in this paper use a modified set of inputs at wavelengths of 400, 500, 675, 870, and $995 \mathrm{~nm}$, with 400 and $500 \mathrm{~nm}$ replacing $440 \mathrm{~nm}$. Note the longest wavelength of $995 \mathrm{~nm}$ replaces the AERONET $1020 \mathrm{~nm}$ due to the wavelength limits of the 4STAR visible spectrometer.

4STAR executed a total of 174 sky scans in ORACLES2016, of which $38 \%$ (66) met the following qualitycontrol (QC) criteria (adapted from the AERONET $\mathrm{QC}$ available at https://aeronet.gsfc.nasa.gov/new_web/PDF/ AERONETcriteria_final1.pdf, last access: 9 July 2019):

- $\operatorname{AOD}(400 \mathrm{~nm})>0.4$

- altitude variation during scan $<50 \mathrm{~m}$;

- total residual sky radiance error; (|measuredfit $\mid)<10 \%$ at all wavelengths;

- measured scattering angle from the minimum of $3^{\circ}$ up to a maximum of at least $50^{\circ}$ (i.e., $\mathrm{SZA}>25^{\circ}$ ) (primarily relevant in almucantar scans); and

- manual inspection of the retrieval output for reasonable residual sky radiance error as a function of scattering angle (i.e., uniform aerosol conditions; no cloud contamination).

Note that, unlike in the AERONET archive, we consider principal plane as well as almucantar scans when the above criteria are met. We do this because due to the timing of 
Table 1. Overview of ORACLES instruments, as used to quantify SSA during the ORACLES campaigns, and the method used. Not all measurement approaches are included in this paper; some are still in process and will be presented in future publications. Instruments/methods presented in this paper are indicated in bold. Full archival data citations are given at the end of the paper under "Code and data availability".

\begin{tabular}{|c|c|c|c|c|}
\hline Instrument & Platform & Method (absorption parameter) & Wavelengths & Required conditions \\
\hline SSFR (+4STAR) & $\mathrm{P}-3$ & $\begin{array}{l}\text { profiles of spectral } \\
\text { irradiance and AOD used } \\
\text { with a radiative transfer } \\
\text { model }(\text { RTM })^{3,4}\end{array}$ & $\begin{array}{l}\text { moderate spectral resolution; } \\
\text { evaluated at } 355,380,452, \\
470,501,520,530,532 \\
550,620,660 \mathrm{~nm}\end{array}$ & $\begin{array}{l}\text { radiation wall/square } \\
\text { spirals above/below } \\
\text { aerosol layer }\end{array}$ \\
\hline PSAP + neph & P-3 & $\begin{array}{l}\text { in situ nephelometer (scattering) } \\
+ \text { PSAP (absorption) })^{5,6}\end{array}$ & $\begin{array}{l}\text { neph: } 450,550,700 \mathrm{~nm} \\
\text { PSAP: } 470,530,660 \mathrm{~nm}\end{array}$ & inside aerosol layer \\
\hline PTI + neph & P-3 & $\begin{array}{l}\text { in situ nephelometer (scattering) } \\
+ \text { PTI (absorption) }\end{array}$ & $\begin{array}{l}\text { neph: } 450,550,700 \mathrm{~nm} \\
\text { PTI: } 532 \mathrm{~nm}\end{array}$ & $\begin{array}{l}\text { inside aerosol layer; } \\
30 \text { s averages on PTI }\end{array}$ \\
\hline $\begin{array}{l}\mathrm{RSP}+ \\
\mathrm{HSRL}-2\end{array}$ & ER-2 & $\begin{array}{l}\text { MAPP algorithm adapted to include } \\
\text { HSRL-2 observed backscatter } \& \\
\text { extinction profiles (vertically } \\
\text { resolved absorption) }\end{array}$ & $\begin{array}{l}\text { RSP window channels } \\
+ \text { HSRL- } 2 \text { channels at } \\
355,532,1064 \mathrm{~nm}\end{array}$ & instrument above aerosol \\
\hline
\end{tabular}

${ }^{1}$ Redemann et al. (2014). ${ }^{2}$ 4STAR codes (see the acknowledgments). ${ }^{3}$ Bergstrom et al. (2010). ${ }^{4}$ Cochrane et al. (2019) ${ }^{5}$ Anderson and Ogren (1998). ${ }^{6}$ Virkkula (2010).

7 Sedlacek and Lee (2007). ${ }^{8}$ Knobelspiesse et al. (2011). ${ }^{9}$ In development, following Segal-Rosenheimer et al. (2018). ${ }^{10}$ Stamnes et al. (2018). ${ }^{11}$ Liu et al. (2019, in development).

$12 \mathrm{Xu}$ et al. (2018). ${ }^{13}$ Dubovik and King (2000).

ORACLES flights, 4STAR sky scans were largely near solar noon, limiting the angular range available in almucantar scans. In addition to the scans meeting the above QC measures, another 16 (9\% of the scans) were included based on manual QC inspection. This generally involved cases with AOD between 0.2 and 0.4 . We retain these lower-AOD, manually QC'd scans to explore the reliability of the retrievals under conditions of lower aerosol loading. This QC procedure retained 82 sky scans in total (47\% of all scans) which produced credible retrievals. In the present study, we focus on a further subset of 75 lower-altitude $(<3 \mathrm{~km})$, QC- screened sky scans. This is because our current interest is in retrievals of aerosol properties through the entire aerosol plume, and thus the low-altitude sky scans are most comparable to the other instruments presented here. Overall, 49 of the QC-passed scans corresponded to valid in situ data and are used in the aggregate comparison figures; an additional 26 did not correspond in space and time to the other instruments but are included in the broader analysis of Sect. 4 . The available sky scan retrievals and their co-location with other instruments are summarized in Table 2. 
The 4STAR uncertainties presented here are quantified by a sensitivity test based on AOD and radiance uncertainties. AOD uncertainties used are the archived wavelengthdependent uncertainties (LeBlanc et al., 2019), and uncertainties in the sky radiances have been quantified through laboratory calibration using a NIST-traceable 12-lamp 36 in integrating sphere (Brown et al., 2005). AOD uncertainties are dependent on wavelength, time, and solar zenith angle (geometrical air mass factor), as well as potential window contamination in some cases. These values were typically between 0.01 and 0.02 , ranging from a low of 0.008 to a high of 0.037 in an extreme case. Radiance uncertainties are wavelength dependent but are constant over the entire campaign, ranging between $1.0 \%$ and $1.2 \%$ for $470-995 \mathrm{~nm}$. To test the impact of these two types of errors, the sky scan inversion code is run separately for an addition or subtraction case for each of these two parameters (i.e., four cases), and the result is added in quadrature for each of the upper and lower bounds. Note that an increase in AOD (without perturbing radiances) results in a lower SSA and higher AAOD, while an increase in radiance (without perturbing AOD) results in a higher SSA and lower AAOD. Uncertainties in SSA are dominated by the AOD terms, with smaller contributions from the uncertainty in the measured sky radiances. Other sources of uncertainty are not explicitly quantified in the present work.

\subsubsection{AirMSPI}

The Airborne Multi-angle SpectroPolarimeter Imager (AirMSPI) is an imaging polarimeter which has been flying on the ER-2 aircraft since October 2010, including in ORACLES-2016 (Diner et al., 2013). The instrument contains a pushbroom camera inside a programmable gimbal for along-track view angles between $\pm 67^{\circ}$, which is typically used for the observation of a $10 \times 10 \mathrm{~km}$ target from nine discrete view angles ("step-and-stare mode"; $10 \mathrm{~m}$ resolution), or a $100 \mathrm{~km}$ long target under a continuously changing view angle ("sweep mode"; $25 \mathrm{~m}$ resolution). Further instrument details may be found in Diner et al. (2013). The sweep view mode was adopted for cloud and above-cloud aerosol observations during the ORACLES field campaign. The AirMSPI data presented here are from a coupled stratocumulus cloud and above-cloud aerosol retrieval based on an optimization approach ( $\mathrm{Xu}$ et al., 2018). The retrieval is run by fitting polarized radiance in a wide scattering angular range (e.g., from $\sim 90$ to $180^{\circ}$ ) at three spectral bands centered at 470, 660, and $865 \mathrm{~nm}$. The retrieved above-cloud aerosol properties include refractive index, size distributions, and aerosol total volume concentration. The retrieved cloud properties include cloud-top droplet size distribution, cloud-top height, and cloud optical thickness (cloud optical thickness is derived by fitting the radiance in the three polarimetric bands). Non-spherical particles are not accounted for in the current retrievals. The column effective AOD and SSA are calculated using
Mie theory. Retrieval uncertainties are reported at the polarimetric wavelengths and are determined by propagating the instrument errors into the retrieval uncertainties. For example, to get the retrieval uncertainty for above-cloud AOD and SSA, the fitting residual and instrument bias are multiplied by the inverse of the Fisher matrix evaluated at the retrieved solution. Then, the chain rule is applied to propagate the error of the retrieved aerosol properties in the solution vector to AOD and SSA, which further involves the use of a Jacobian matrix containing derivatives of AOD and SSA with respect to aerosol properties (Xu et al., 2018, 2019).

\subsubsection{HiGEAR (PSAP + nephelometer)}

The Hawaii Group for Environmental Aerosol Research (HiGEAR) operated several in situ instruments on the P3. Total and submicrometer aerosol light scattering coefficients $\left(\sigma_{\text {scat }}\right)$ were measured onboard the aircraft using two TSI model 3563 three-wavelength nephelometers (at 450,550 , and $700 \mathrm{~nm}$ ) corrected according to Anderson and Ogren (1998). In addition to the TSI nephelometers used in the present work, two single-wavelength nephelometers (at $550 \mathrm{~nm}$, Radiance Research, M903) were operated in parallel to study the increase in light scattering as function of RH. The humidified M903 nephelometer was operated near $80 \%$ RH, while the dry unit was maintained below $40 \%$ (Howell et al., 2006). Discussion of the impacts of aerosol humidification in the context of comparison with remotesensing retrievals at ambient $\mathrm{RH}$ is found in Sect. 4.2.

Light absorption coefficients $\left(\sigma_{\text {abs }}\right)$ at 470, 530, and $660 \mathrm{~nm}$ were measured using two Radiance Research PSAPs. The humidity within the PSAP was not explicitly controlled, but the PSAP optical block was heated to approximately $50{ }^{\circ} \mathrm{C}$ to reduce artifacts which would result from a changing $\mathrm{RH}$; this had the effect of reducing relative humidity in this instrument to much lower than the $40 \%$ within the nephelometers. The PSAP absorption corrections were performed according to an updated algorithm (Virkkula, 2010). Instrumental noise levels are $0.5 \mathrm{Mm}^{-1}$ for a $240-300 \mathrm{~s}$ sample average, comparable to values reported previously (Anderson et al., 2003; McNaughton et al., 2011). In this paper, we primarily present results calculated with the wavelengthaveraged (as opposed to the wavelength-specific) correction factors presented in Virkkula (2010). Further discussion of this decision and the differences between the two corrections are shown in Appendix A1.

SSA was calculated using the measured PSAP absorption combined with dried $(\mathrm{RH}<40 \%)$ TSI nephelometer scattering interpolated to PSAP wavelengths. In the comparison cases (i.e., column values), SSA is the extinction-weighted (extinction is defined as the sum of scattering and absorption) profile average according to the following procedure. To reduce noise, the reported $1 \mathrm{~s}$ scattering and absorption data, corrected to ambient temperature and pressure, were first av- 
eraged to $30 \mathrm{~s}$ box-car averages. Time-averaged data are then filtered to reject cases where $\sigma_{\text {scat, }, 530 \mathrm{~nm}, 30 \mathrm{~s}}<10 \mathrm{Mm}^{-1}$ to assure an adequate signal-to-noise ratio. Data are also discarded if $>20 \%$ of the archived 1s SSAs are undefined over the averaging period, to account for manual quality flagging of SSA due to, e.g., calibration periods. Applying different averaging times (10-60 s averages) did not result in appreciably different SSA and Ångström exponents for the column average. SSA is then calculated as SSA $=\sigma_{\text {scat }} /\left(\sigma_{\text {scat }}+\sigma_{\text {abs }}\right)$ and then arithmetically weighted by its extinction in computing a profile average. In the AOD proxy shown in Sect. 3.1, due to the vertical integration involved, scattering and absorption data were instead averaged into equal $100 \mathrm{~m}$ vertical bins (approximately $15 \mathrm{~s}$ of flight time) and integrated over the full profile; in this specific case, only profiles with altitudes spanning at least 1.6 to $5.1 \mathrm{~km}$ are considered (Table 2).

Unless otherwise specified, the "in situ" data reported in this paper are from the PSAP + nephelometer combination, with Virkkula wavelength-averaged corrections applied. Due to the uncertain nature of the impacts of humidification on each of the scattering and absorption components individually and how they affect the resulting SSA, we leave these in situ data as dried. The basis for and implications of this decision are discussed in more detail in Sect. 4.2.

\subsubsection{PTI + nephelometer}

The second in situ measurement of aerosol absorption uses data from the airborne photothermal interferometer (PTI). The PTI measures aerosol light absorption by combining photothermal spectroscopy and laser interferometry (Sedlacek, 2006; Sedlacek and Lee, 2007). The hallmark of the PTI, and other photothermal-based techniques, is a complete immunity to light scattering. The unit deployed during ORACLES-2016 operated at a wavelength of $532 \mathrm{~nm}$. While the baseline noise on the ground was $\sim 1.5 \mathrm{Mm}^{-1}$ for a $1 \mathrm{~s}$ integration time, the PTI exhibited pronounced sensitivities to aircraft platform vibrations during the 2016 ORACLES campaign. These unexpected sensitivities had two immediate, and unrecoverable, effects on the performance of this measurement onboard the P-3. First, the noise floor increased to $\sim 20 \mathrm{Mm}^{-1}$ at $1 \mathrm{~s}$ in flight, due to difficulties in maintaining quadrature lock with the active quadrature lock feedback circuit. Second, platform vibration impacted the laser beam overlap between the modulated excitation laser operating at $532 \mathrm{~nm}$ and the $632 \mathrm{~nm}$ interferometer laser beam. Reduction in beam overlap resulted in an underreporting of the actual aerosol absorption since the probe beam (interferometer) was not optimally sampling the volume illuminated by the modulated green beam. Additionally, laser overheating further limited the operation of this instrument to in-plume transects.

Due to these performance impacts, the 2016 PTI data are flagged as suspect. As such, the PTI data are archived as $30 \mathrm{~s}$ averages, with an uncertainty of $\sim 4 \mathrm{Mm}^{-1}$ subjected to the $1 \mathrm{~s}$ measurement noise floor, and with data available only for some periods and for a subset of P-3 flights. As these data are included in the ORACLES 2016 archive, we include a discussion of them in this comparison study, though with the above caveats. In the comparison case study which has PTI data available (Sect. 3.1.2), the extinction-weighted SSA was only able to be calculated from the PTI absorption using data within the time period of the P-3 comparison case (profile and in-plume leg), rather than a complete profile as with the PSAP + neph SSA. Due to the limitations with these data as described above, we do not show the PTI + neph SSA for this case but discuss it in qualitative terms in Sect. 3.1.2. A direct comparison of the absorption as measured by the two in situ instruments (PTI and PSAP) is shown in Appendix A2.

A redesign of the PTI, based in part upon lessons learned during the 2016 campaign, saw improved performance for the 2018 ORACLES campaign and will be the subject of another paper.

\subsubsection{RSP}

The NASA GISS Research Scanning Polarimeter (RSP) is a multi-angle, multi-spectral polarimeter aboard the ER-2 that measures the Stokes parameters $I, Q$, and $U$ at $\sim 150$ angles between $\pm \sim 60^{\circ}$ in the along-track direction, in nine spectral channels centered at $410^{*}, 469^{*}, 555^{*}, 670^{*}, 864^{*}, 960$, 1594*, 1880, and 2264* nm (Cairns et al., 1999). The seven channels denoted by an asterisk have negligible or weak and correctable water vapor absorption and were used in the microphysical aerosol properties from polarimetry (MAPP) retrieval. The RSP MAPP algorithm (Stamnes et al., 2018) was adapted for ORACLES observations of aerosols above water by incorporating into the retrieval an aerosol profile consisting of two layers (a top layer of fine-mode aerosol located at $2.25-5.5 \mathrm{~km}$, and a base layer of coarse-mode (sea salt) aerosol located at $0-1 \mathrm{~km}$ ) as approximately identified by the High Spectral Resolution Lidar (HSRL-2), which is also on the ER-2 aircraft. The aerosols are modeled as a bimodal population of spherical fine- and coarse-mode aerosols, with each mode defined by a lognormal size distribution. The finemode aerosol effective radius, effective variance, and complex refractive index are then retrieved. The coarse-mode aerosol is assumed to consist of non-absorbing spherical particles with complex refractive index equal to that of water, except the real part was multiplied by a factor of 1.01. The maximum allowed wind speed for the one-dimensional CoxMunk ocean was increased to $12 \mathrm{~m} \mathrm{~s}^{-1}$ to allow retrieval of high wind speeds consistent with Modern-Era Retrospective analysis for Research and Applications version 2 (MERRA2) profiles.

Since for RSP the fine and coarse modes are retrieved separately, the total AOD is thus the sum of the fine- plus coarsemode optical depths. Due to the assumption that coarse-mode aerosol is non-absorbing sea salt, the AAOD and Ångström 
exponent values are provided for the fine mode only to allow for more direct comparisons to the smoke properties retrieved by the remote sensors above clouds.

\subsubsection{SSFR}

The SSFR is a moderate resolution radiative flux (irradiance) spectrometer covering the wavelength range from 350 to $2100 \mathrm{~nm}$ (Pilewskie et al., 2003; Schmidt and Pilewskie, 2012). The downwelling (zenith) and upwelling (nadir) solar radiation is collected by light collectors mounted to the skin of the aircraft. In the past, aerosol absorption, SSA, and the asymmetry parameter were derived from irradiance pairs collected along collocated horizontal legs above and below the layer (Schmidt et al., 2010). For ORACLES, this approach was impractical because of the underlying albedo variability in the presence of clouds. The alternative is to measure the irradiances in a vertical profile, realized as a spiral. This was not an option for previous experiments where the zenith light collector was fix-mounted to the aircraft, introducing uncertainties due to the changing aircraft attitude that cannot be corrected for after the fact. Specifically for ORACLES, an active leveling platform (ALP) was built for the zenith light collector on the P-3 aircraft. By controlling its angular position, SSFR is able to obtain zenith (downwelling) irradiance measurements throughout the vertical profile if the spirals include short $(\sim 9-30 \mathrm{~s})$ straight segments (typically offset by $90^{\circ}$ in heading). This spiral profile maneuver with short straight legs is referred to as a square spiral. The nadir (upwelling) irradiance measurements are affected by the underlying cloud and its variability, as well as by the aerosol between the cloud top and the nadir light collector. To separate the aerosol signal from that of clouds, SSFR uses the upwelling irradiance at $1.6 \mu \mathrm{m}$ where the signal is dominated by clouds and filters the data such that only points within 1 standard deviation of the mean are included for final processing. The impact of the aerosol layer on the downwelling and upwelling irradiance is then quantified throughout the spiral by plotting spectral irradiance profiles with 4STAR-reported above-aircraft AOD at $532 \mathrm{~nm}$ as the vertical coordinate. A linear fit is performed on both upwelling and downwelling irradiance, using AOD as the vertical coordinate. The absorption is then derived from the difference of the net irradiance at the top and the bottom of the layer (Cochrane et al., 2019). Since this approach uses data throughout the vertical profile, it is a more robust and accurate method than obtaining it just from the irradiance pairs above and below the layer as in a radiation wall. More importantly for measurements above clouds, this method minimizes the impact of cloud variability on the sampling of upwelling irradiances through the filtering approach described above. Any deviations from a linear relationship between AOD and irradiances are attributable to changes in the underlying cloud albedo. The filtering technique allows separation of these influences from those originating from the aerosol layer. SSA is retrieved with an al- gorithm that iteratively changes SSA and asymmetry parameter until the modeled irradiance profiles (based on 4STAR AOD and SSFR-derived cloud albedo) match the measurements (Schmidt et al., 2010). This SSA retrieval is done independently for each wavelength, without applying spectral smoothness constraints. Uncertainties in SSFR SSA as reported here reflect the $1 \sigma$ uncertainty as calculated from the probability of the SSA and asymmetry parameter pair within the retrieval. A description of the algorithm and the uncertainty analysis may be found in Cochrane et al. (2019).

\subsection{Instrument intercomparison conditions}

Comparison cases were selected based on the available instrument data and the flight path for a given day. Identified cases included at least two of the following conditions to facilitate comparison between instruments:

1. operational nephelometer plus PSAP and/or PTI in situ data during an aircraft profile (either a ramp or a square spiral as described in Sect. 2.1.6);

2. $\geq 1$ sky scan (4STAR) at or below the bottom of the plume (i.e., measuring the total-column aerosol properties);

3. a square spiral profile through the full column (SSFR); and

4. an ER-2 overpass of the P-3 location (RSP and/or AirMSPI).

Due to the different flight patterns necessary for the different instruments to measure/retrieve aerosol properties, this yielded 24 potential comparison case studies over 12 (out of 14) flight days (Fig. 2). Within this set of cases, temporal separation between measurements from different instruments varies between $10 \mathrm{~min}$ and $2 \mathrm{~h}$; the inter-measurement spatial spread was within approximately $1^{\circ}$ in either latitude or longitude (ideally $100 \mathrm{~km}$ or less but up to $130 \mathrm{~km}$ in select cases). Note that not all instruments were available for each comparison (Table 2). In selecting comparison periods, spatial coincidence was given priority over temporal coincidence. All comparison cases included at least one 4STAR sky scan; this was reduced to 20 cases when we required QCscreened sky scans below $3 \mathrm{~km}$ (considered to be below the bulk of the aerosol plume), 19 of which were coincident with an in situ profile. Of the 24 cases, 14 had full profiles and 9 had partial profiles only, for a total of 23 of the 24 with in situ observations of SSA.

Below, we focus in on two specific case studies on 12 and 20 September 2016. The case on 12 September (blue star in Fig. 2) was a mostly cloudless scene and included RSP retrievals from an ER-2 overpass. For the case on 20 September (orange star in Fig. 2), valid SSFR retrievals were run using data from a P-3 square spiral maneuver through a cloudy scene overlaid with substantial aerosol loading. Each of the 


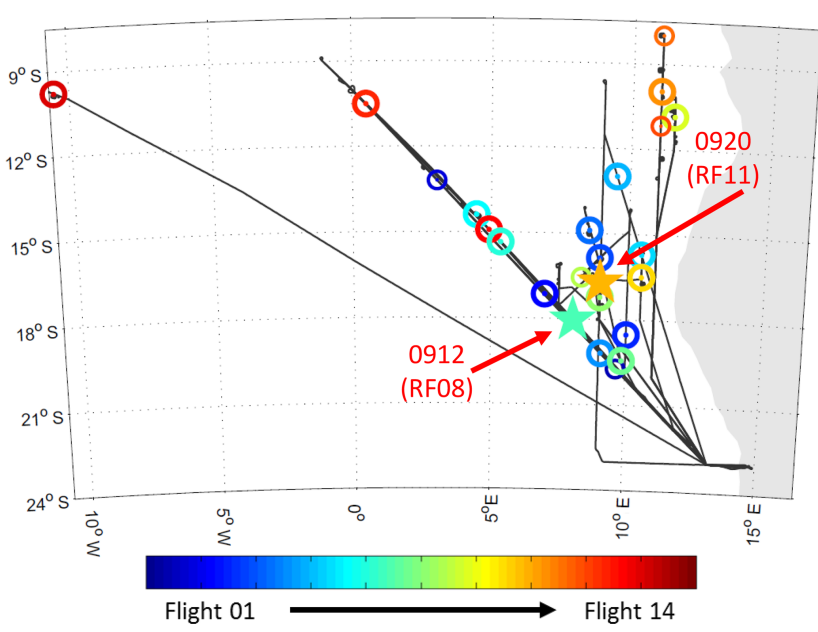

Figure 2. ORACLES-2016 P-3 flight paths (all flights; black lines) showing the approximate location of all aerosol comparison cases (circles). The cases highlighted in this paper (12 and 20 September 2016) are indicated by a star and arrow, and larger circles are the cases included in the analysis in Sect. 3.2. The color indicates the timing of an individual case within the September 2016 deployment.

12 ER-2 flights (including transits to/from Namibia) yielded AirMSPI above-cloud aerosol (ACA) retrievals somewhere over the SEA; nine of the P-3 comparison cases included ER-2 overpasses, and each of these had at least one AirMSPI ACA retrieval co-located with P-3 observations. Three of these cases (including the case from 20 September discussed in Sect. 3) had retrievals with the highest confidence (labeled "primary" in Table 2); retrievals were run for an additional six cases, which are included in Sect. 4 to allow for broader comparison. However, these second-tier retrievals have somewhat increased potential for retrieval biases, due to small scattering angle coverage and/or broken cloud conditions. Successful above-cloud aerosol retrievals for data from the RSP have been processed for one of the cases thus far (the case study on 12 September). While the present work is thus limited to a subset of the 24 cases, future comparative analysis may be able to expand the number of cases to incorporate potential newly available data (Table 1 ).

It is important to note that due to the different instrument methodologies, exact spatiotemporally coincident measurements are not possible, if for no reason other than the different viewing geometries alone; the comparisons presented here are chosen for their potential to obtain measurements of reasonably similar aerosol properties from different perspectives (e.g., below- versus above-aerosol remote sensing, and remotely sensed versus in situ; Fig. 3). In our analysis, we first present the two individual case studies (Sect. 3.1) before discussing results from the aggregation of all coincident measurements from three of the instruments (Sect. 3.2).

\section{Results}

\subsection{Multi-instrument case studies}

We next show two specific case studies, from flights on 12 and 20 September 2016, where six of the methods can be compared.

\subsubsection{Case study: 12 September 2016 (broken cloud/clear sky)}

The P-3 flight on 12 September was a radiation-targeted flight of opportunity, with two potential comparison cases identified. Both cases are included in the analysis in Sect. 3.2, but in this section we focus on the second case, at approximately $18.0^{\circ} \mathrm{S}, 8.0^{\circ} \mathrm{E}$, between $13: 44$ and 14:34 UTC (Fig. 2). This case starts with two consecutive 4STAR sky scans at approximately $1 \mathrm{~km}$ altitude (above-cloud level; also referred to below as "plume only" within this section for reasons which are explained below) over a broken cloud scene of albedo of 0.1 , followed by a short descent and two scans at $80 \mathrm{~m}$, which is below typical cloud level but was, in this case, in a cloudless area (scene albedo approximately 0.05 ). The P-3 then flew a ramped ascent from $80 \mathrm{~m}$ to $5.8 \mathrm{~km}$, ending above the top of the aerosol plume. Measured $\mathrm{RH}$ throughout the plume increased from near $0 \%$ below the plume level (up to $\sim 2.5 \mathrm{~km}$ ) to a maximum of around $50 \%$ at plume top $(5 \mathrm{~km})$, i.e., generally below the $\mathrm{RH}$ of $40 \%$ "dry" threshold for the in situ instrumentation. This corresponds to a roughly constant water vapor mixing ratio: around $5000 \mathrm{ppmv}\left(3.1 \mathrm{~g} \mathrm{~kg}^{-1}\right)$ through the plume. The first pair of sky scans (at $1 \mathrm{~km}$ altitude) are separated from the second pair (at $80 \mathrm{~m}$, at the base of the ramp) by approximately $20 \mathrm{~min}$ and $130 \mathrm{~km}$. While this is slightly outside our desired spatial constraints which may give slightly poorer scene agreement for this comparison case, we believe it instructive to retain the two above-boundary-layer sky scans in examining this case. First, this facilitates better comparison with RSP (which retrieves above-cloud fine-mode aerosol separately) and second, since the bulk of the ORACLES-2016 data consists of plume-only aerosol without boundary-layer influence, the inclusion of these scans allows for better contextualization of this specific case. The ER-2 overpass of the scene, occurring during the $\mathrm{P}-3$ 's ascending ramp, resulted in 20 RSP retrievals between 14:17 and 14:21 UTC. There were no AirMSPI retrievals during this period.

Figure 4 shows the SSA for each of the available instruments for this case. The most notable feature is in the 4STAR sky scans; while the retrievals agree quite well at short wavelengths (within $\sim 0.01$ and well within 4STAR's SSA uncertainty range determined by AOD and radiance uncertainties, as described in Sect. 2.1.1), at the longer wavelengths the two sets of scans diverge markedly. It may be noted that the uncertainty increases as well at these longer wavelengths, and there is overlap in the two sets of uncertainty 
Table 2. Summary of data available for instruments with multiple comparison cases (i.e., from 4STAR, AirMSPI, and in situ instrumentation), for campaign-wide statistics (top row; Sect. 4) and for comparison with other instruments (lower rows; Sect. 3).

\begin{tabular}{|c|c|c|c|c|}
\hline & 4STAR (P-3) & AirMSPI (ER-2) & $\begin{array}{l}\text { In situ (P-3): } \\
\text { full profile }\end{array}$ & $\begin{array}{r}\text { In situ: } \\
\text { partial profiles only }\end{array}$ \\
\hline No. valid retrievals & 75 (below $3 \mathrm{~km}$ ) of 82 (total) & 134 (primary) +68 (additional) & continuous & continuous \\
\hline No. cases total & 19 & 9 & 14 & 9 \\
\hline vs. 4STAR & - & 9 & 11 & 14 \\
\hline vs. AirMSPI & 9 & - & 6 & 3 \\
\hline vs. in situ & 19 & 9 & - & - \\
\hline
\end{tabular}

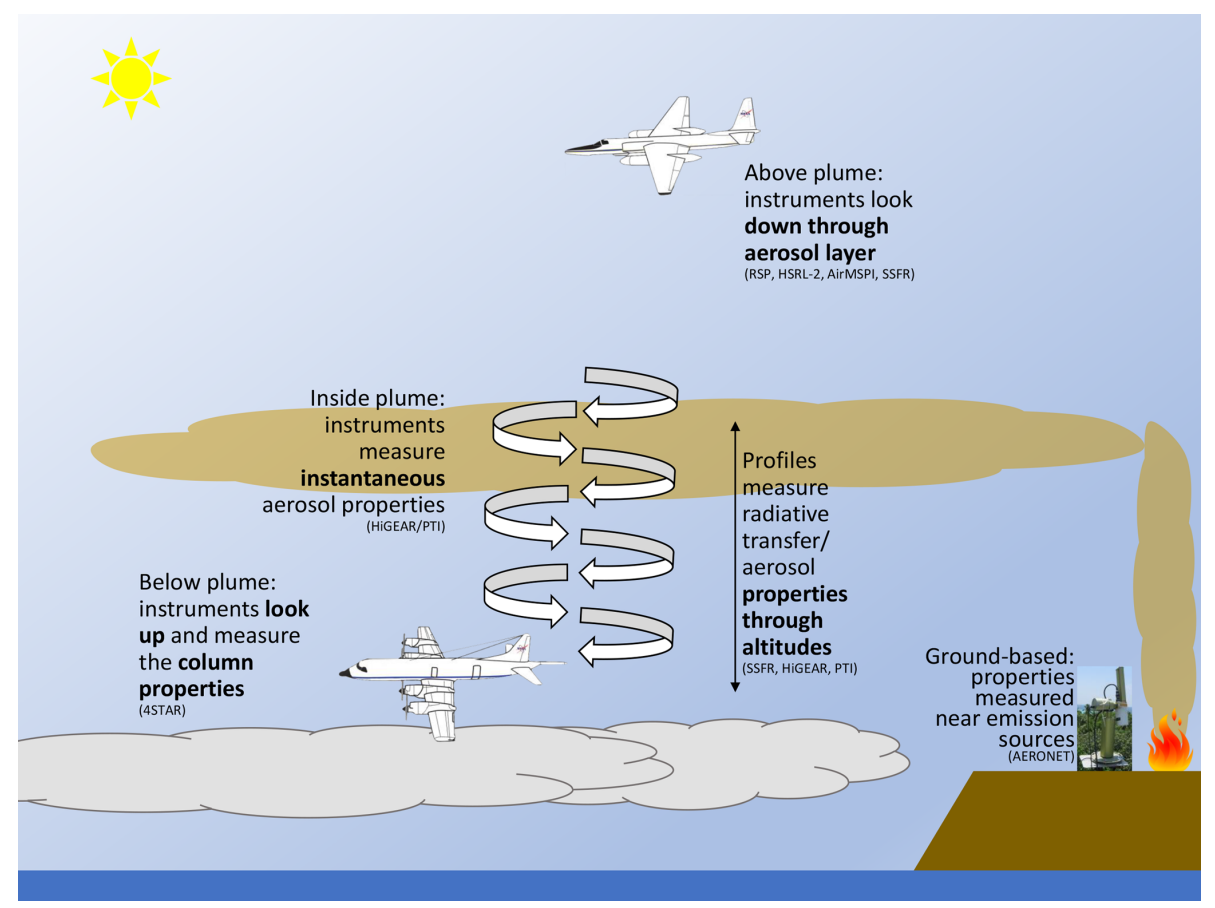

Figure 3. Schematic illustrating the different successive measurement orientations necessary for a comparison of aerosol properties using different instruments and aircraft in an aerosol-above-cloud environment. The aircraft shown are those used in ORACLES: the high-altitude (30 km) ER-2 (top) and the propeller P-3B aircraft (bottom) for tropospheric sampling (approximately 0-7 km).

estimates. The two sky scans performed near the surface (at $80 \mathrm{~m}$ altitude), immediately before the start of the ascending ramp, agree well with one another and give a higher longwavelength SSA than the two scans performed above the boundary layer (at $1 \mathrm{~km}$ altitude). However, the $1 \mathrm{~km}$ scans are more representative of the typical SSA spectral shape observed from 4STAR for the ORACLES-2016 campaign as a whole (i.e., monotonically decreasing for wavelengths $\geq 500 \mathrm{~nm}$ ). As the majority of the 4STAR sky scans were taken above the boundary layer, the increase in SSA at longer wavelengths as seen in the two $80 \mathrm{~m}$ scans likely reflects contribution from sea salt in the boundary layer, combined with the overlying biomass burning aerosol. In situ measurements report $\sigma_{\text {scat }, 530 \mathrm{~nm}}$ of around $30 \mathrm{Mm}^{-1}$ between 80 and $600 \mathrm{~m}$ with negligible absorption in these altitudes, suggesting purely scattering sea salt. This is additionally corrobo- rated by the HSRL-2 retrievals of aerosol type, which identified marine aerosol below the smoke plume around this time. The AERONET climatology of aerosol from "desert dust and oceanic" sites (Bahrain/Persian Gulf, Cabo Verde, and Lanai, HI, sites) by Dubovik et al. (2002) shows high, largely spectrally flat or slightly increasing SSA between 440 and $1020 \mathrm{~nm}$. Indeed, LeBlanc et al. (2019) also found lower extinction Ångström exponents for "full-column" (i.e., below cloud level) 4STAR AOD measurements than for those taken above the boundary layer, which is consistent with the differences seen in this case (Fig. 5).

In situ measurements show a similar spectral SSA compared with the other two instruments. We note that if we apply the wavelength-specific, rather than wavelengthinvariant, Virkkula corrections to the PSAP data, the PSAP + neph SSA shows a different spectral shape, with a 


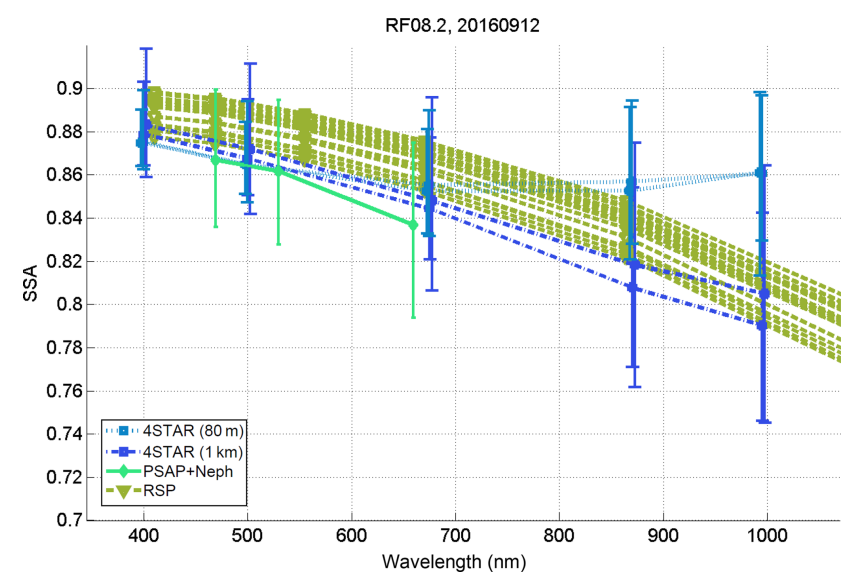

Figure 4. Spectral SSA from 4STAR (blue squares), RSP (goldenrod triangles), and in situ (green diamonds) calculations for the case on 12 September 2016. This case was centered at approximately $18.0^{\circ} \mathrm{S}, 8.0^{\circ} \mathrm{E}$, between 13:44 and 14:34 UTC. The bars on the in situ measurements represent the 10th-90th percentile ranges for the profile considered. The two 4STAR curves with high SSA995 nm are from the $80 \mathrm{~m}$ altitude scans, while the curves with low $\mathrm{SSA}_{995 \mathrm{~nm}}$ curves are from the $1 \mathrm{~km}$ altitude scans.

small maximum in SSA at $530 \mathrm{~nm}$ (Appendix A1). It is also important to note that the in situ measurements will exclude a significant portion of the coarse-mode aerosol due to poor inlet passing efficiency of larger aerosol particles (a $50 \%$ size cut around $\sim 4 \mu \mathrm{m}$ ). This means that nominally there are twice as many $4 \mu \mathrm{m}$ particles observed by remote-sensing instruments compared with in situ, and perhaps 10 times as many at larger sizes $(10-20 \mu \mathrm{m})$, and thus even full-column (to the extent possible using P-3 data) in situ values may be missing larger aerosol. Thus, the SSA and AEs derived from the in situ instruments will have a greater contribution from the biomass burning aerosol than will the values retrieved from 4STAR (and in the later comparison case, AirMSPI and SSFR), which include all ambient aerosol (as noted above, RSP models fine- and coarse-mode aerosol separately). The differences in SSA values are also within the instrument uncertainty (4STAR) and variability (in situ) ranges.

Figure 5 shows the AAOD and AOD for this same case. Of the measurements from 4STAR, the two $80 \mathrm{~m}$ cases have slightly higher AOD than the $1 \mathrm{~km}$ measurements at $400 \mathrm{~nm}$ ( 0.45 versus 0.42 ; AOD uncertainty \pm 0.018$)$ but significantly higher AOD at $995 \mathrm{~nm}(0.18$ versus 0.11 ; uncertainty \pm 0.02$)$. Thus, the $80 \mathrm{~m}$ values have markedly lower Ångström exponents - a difference of 0.4 for both SAE and EAE. This is again consistent with a significant coarse-mode component in the aerosol between $80 \mathrm{~m}$ and $1 \mathrm{~km}$ (i.e., the boundarylayer aerosol) - for this region, very likely sea salt. Comparison with the $1 \mathrm{~km}$ 4STAR sky scans is additionally instructive for this case as due to the very low absorption data (and consequent low signal-to-noise ratio) in the boundary layer, the SSA values were not reported for these altitudes; thus, the in situ values in Fig. 4 are effectively averaged over only plume altitudes, contributing to the lower "AOD" from in situ reported here. Given that RSP and 4STAR both measure the full column (including this coarse mode), we expect the retrieved column SSA to be somewhat higher than that from the measurements/retrievals of SSA for the aerosol for the BB plume altitudes only; this could be contributing to the higher SSA from RSP and to a lesser degree from 4STAR as compared with in situ instrumentation (Fig. 4). Based on this, we might also expect the 4STAR-retrieved SSA to be higher for the retrievals from $80 \mathrm{~m}$ than from $1 \mathrm{~km}$, and this is not apparent except at wavelengths $870 \mathrm{~nm}$ and longer. However, this could potentially be explained simply by a smaller relative contribution of boundary-layer aerosol to the total aerosol loading, particularly at the shorter wavelengths (i.e., the smaller difference between the two sets of sky scans at shorter wavelengths).

The AAE and EAE are given by the slopes of the AAOD and AOD versus wavelength, and the SAE can be inferred from the two (Fig. 5). In comparing with the other instruments in this case study, the $1 \mathrm{~km}$ altitude 4STAR EAEs and SAEs are more comparable to those derived from the in situ instruments. The 4STAR SAE and EAE values from $80 \mathrm{~m}$ (including sea salt) are lower than the corresponding RSP Ångström exponents of $\mathrm{AOD}_{\text {fine+coarse. The 4STAR }}$ $1 \mathrm{~km}$ values (plume only) agree with the RSP AOD fine only for mid-visible values, and the two diverge for wavelengths greater than $700 \mathrm{~nm}$, which may somewhat be expected given the lower signal at longer wavelengths. While RSP observes slightly higher AOD (compared with 4STAR) at shorter wavelengths, at the longer wavelengths the RSP AOD is less than the $80 \mathrm{~m}$ values (i.e., 4STAR measurements with additional coarse-mode aerosol) but still greater than the $1 \mathrm{~km}$ values. The in situ AOD proxy is again using dried values for consistency with the SSA values shown. The in situ is notably lower than the remote-sensing methods, as may be expected: while this profile extended above the plumetop height (as seen by HSRL-2), thus including the bulk of the aerosol, the altitude limitations may give integrated AODs which are slightly lower than the remote-sensing instruments. In addition to this, the drying of the in situ scattering and absorption will also reduce the calculated optical depths, though for this case, the plume RH is largely less than $40 \%$, with a brief maximum of $49 \%$ at plume top. As such, we expect the effect of humidification on the scattering to be less than $5 \%$ (based on the dry/wet nephelometer data), which has an effect of increasing the in situ AODs by 0.010.02 . The lower in situ AOD values are likely primarily due to the inlet limitations described above; these instruments are likely missing larger particles seen by the remote-sensing instruments.

In terms of AAE, the RSP results give higher values (1.251.26) than 4STAR, similar to the AAE from the PSAP (1.23). The average 4STAR AAOD $400 \mathrm{~nm}$ is 0.057 measured at $80 \mathrm{~m}$ and is 0.049 at $1 \mathrm{~km}$, and $\mathrm{AAOD}_{995 \mathrm{~nm}}$ is 0.025 versus 0.023 
(a)

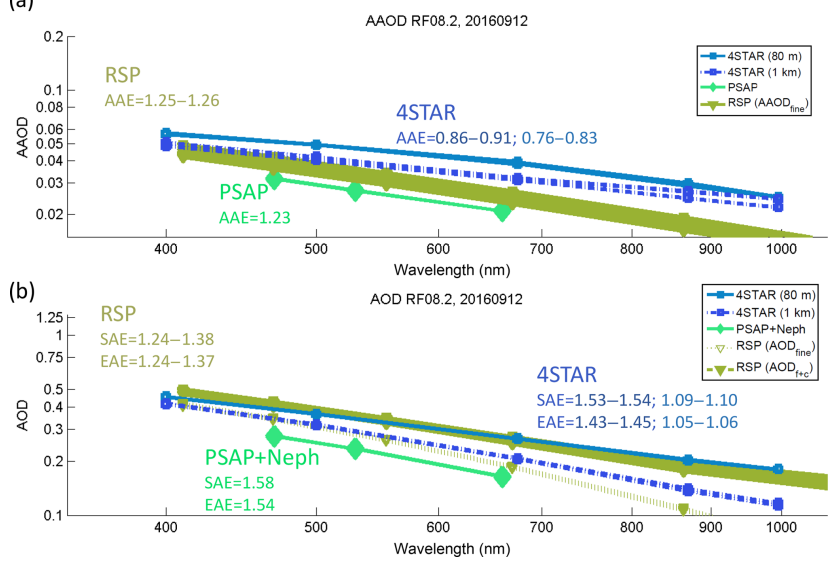

Figure 5. Spectral (a) AAOD and (b) AOD from 4STAR, RSP, and the in situ calculations for the case on 12 September 2016, as well as the AAE, SAE, and EAE values (derived from the slopes in log$\log$ space of AAOD and AOD). RSP EAE and SAE include fineplus coarse-mode AODs, whereas RSP AAE are for fine mode only. Note that the in situ vertical profile for this case extended from $80 \mathrm{~m}$ to $5.8 \mathrm{~km}$ and may have undersampled the coarse-mode sea salt at lower altitudes due to inlet efficiency, whereas the two remotesensing instruments give full-column values above the P-3 (4STAR) to the top of the atmosphere, or below the ER-2 (RSP), extending to the surface. For the given 4STAR Angström exponents, the first set refers to the sky scans from $1 \mathrm{~km}$, and the second set refers to the scans from $80 \mathrm{~m}$, immediately before the aircraft ascent.

at $80 \mathrm{~m}$ and $1 \mathrm{~km}$, respectively, though the latter value is an average between 0.024 and 0.022 . The resulting 4STAR AAE values for $80 \mathrm{~m}$ versus $1 \mathrm{~km}$ are more comparable than the pairs of SAE or EAE values: 0.79 versus 0.89 , consistent with minimal contribution of sea salt to aerosol absorption. However, these values are somewhat lower than may be expected from theory; a more detailed discussion of the AAEs over the full campaign is found in Sect. 3.2 below.

\subsubsection{Case study: 20 September 2016 (cloudy scene)}

The flight on 20 September (P-3 RF11) was focused on measuring atmospheric radiation with two parallel N-S flight lines along 9 and $10.5^{\circ} \mathrm{E}$. We again identify two cases which are suitable for the instrument comparison (one on each longitude line, 10.5 and $9^{\circ} \mathrm{E}$ ). Here, we focus on the second of these two cases (P-3 RF11.2), which allowed for comparison of SSA measured by the in situ instruments and 4STAR on the P-3 with retrievals of SSA from both AirMSPI (on the ER-2) and SSFR (on the P-3) (as with RF08, both cases are included in the analysis in Sect. 3.2). This case was centered at approximately $16.7^{\circ} \mathrm{S}, 9^{\circ} \mathrm{E}$, and began at 10:45 UTC with a partial profile descent (ramp) from plume level $(4.3 \mathrm{~km})$ to above-cloud $(600 \mathrm{~m})$ altitude, followed by six sky scans at above-cloud/below-plume altitude between 10:59 and 11:08 UTC, with below-aircraft scene albedo be- tween 0.45 and 0.62. Of these, two scans passed QC (the others were excluded due to high solar elevation on almucantar scans and/or high error in the retrieval results). After the above-cloud leg, there was one ascending full-profile square spiral maneuver ( $370 \mathrm{~m}$ to $7.1 \mathrm{~km}$ ) from approximately 11:52 to 12:15 UTC which provided the observations used in the SSFR retrievals. Three ER-2 overpasses occurred along this longitude line; the AirMSPI retrievals are from overpasses during the first (northward; 11:41-11:51 UTC) and second (southward; 12:18-12:25 UTC) passes. The HSRL-2 lidar retrievals show that this case consisted of an aerosol layer of primarily smoke with contribution by dust of 10\%-15\% of the $532 \mathrm{~nm}$ AOD, with a layer top height between $\sim 5.5$ and $6 \mathrm{~km}$ and extending down to cloud-top height. Measurements from the HiGEAR Aerodynamic Particle Sizer (APS) also saw dust during this profile and indicated that $<10 \%$ of scattering was due to dust. For this case, the above-boundarylayer (BL) RH was somewhat greater and also more varied with altitude compared to the case from 12 September: between $10 \%$ and $80 \%$ through the atmospheric profile (water vapor mixing ratios ranging from 3500 to $13500 \mathrm{ppmv}$, or 2.2 to $8.4 \mathrm{~g} \mathrm{~kg}^{-1}$ ), though RH remained below $40 \%$ except for the plume maximum between 4.2 and $5.6 \mathrm{~km}$. Again, we note that while the remote-sensing (4STAR, AirMSPI, and SSFR) SSAs are measured at ambient humidity, the in situ $(\mathrm{PSAP}+$ neph and PTI + neph) values are for aerosol dried to $\mathrm{RH}<40 \%$. While this difference was minimal for the first case (12 September) due to the generally lower RH, it has the potential to be higher for the second case (20 September). We discuss the implications of aerosol humidification in more detail in Sect. 4.2.

Figure 6 shows the spectral SSA from each instrument available for this case. We first note the general agreement between most instruments (within the stated uncertainties). While 4STAR and AirMSPI both show SSA decreasing at longer wavelengths, 4STAR reports slightly lower SSA values (particularly at longer wavelengths) than AirMSPI. This is a common feature seen in most of the comparison cases (e.g., Fig. 8a-c). The in situ observations have less wavelength range than 4STAR and AirMSPI but again show a decrease in SSA at its longer wavelength. The rate of decrease from 530 to $660 \mathrm{~nm}$ is seen to be greater than from 470 to $530 \mathrm{~nm}$ (this is also seen in the Ångström exponents calculated from two-wavelength pairs, discussed in Sect. 3.2). As in Fig. 4, the wavelength-specific Ångström exponents give a different SSA spectral shape with a small maximum at $530 \mathrm{~nm}$; this artifact (Fig. A2) was more pronounced here than in the case in Fig. 4, possibly due to the greater aerosol loading in this case.

As was discussed in Sect. 2.1.4, the 2016 PTI absorption data are considered more suspect than the other instrument retrievals, and thus we exclude the PTI + neph-derived SSA from this case to focus our analysis on the more robust methods. We briefly note that PTI + neph $\mathrm{SSA}_{532 \mathrm{~nm}}$ for the available cases (including this one) is higher than the 
PSAP + neph SSA. This result is expected in light of the lower reported absorption by the PTI (Fig. A3). Additionally, due to limited PTI data at lower (below-plume) altitudes, the values going into the average value are likely biased towards the higher altitudes of the plume itself. This is relevant, as the PSAP + neph vertically resolved data consistently show SSA values which were higher at higher altitudes, and thus this sampling pattern of the PTI (i.e., preferentially at higher-SSA altitudes) may also contribute somewhat to the PTI's higher SSA relative to the column-average extinction-weighted PSAP + neph. The vertical structure of SSA, its spatial patterns, and relation to other ORACLES data are not explicitly discussed here but will be the focus of future papers.

The SSFR retrieval largely agrees with 4STAR, AirMSPI, and the in situ data (again within the given instrument uncertainties) for mid-visible wavelengths, though it reports lower SSA for the shorter $(<440 \mathrm{~nm})$ wavelengths. The spectral shape is somewhat more spectrally flat but is consistent for all retrieved wavelengths to within the instrument uncertainty. Note that the retrieval at each individual wavelength is performed separately for SSFR. This is in contrast to 4STAR, AirMSPI, and RSP, which involve assumptions about aerosol size distributions and particle shape. In addition, for these instruments, the spectral refractive indices are retrieved by fitting all wavelengths simultaneously: a spectral smoothness constraint is imposed on the real and imaginary parts of the aerosol refractive index to improve the retrievals. For 4STAR, this means that the inversion algorithm may converge to a different result based on small perturbations in the wavelength-dependent AOD and radiance values used as inputs; this range is what we attempt to encapsulate within the stated uncertainty bars. For AirMSPI, the polarized radiances measured in the 470,660 , and $865 \mathrm{~nm}$ bands have less sensitivity to aerosol refractive index and coarse-mode aerosol size than to aerosol loading and cloud microphysical properties. As a result, the AirMSPI retrieval accuracy of refractive index and coarse-mode aerosol size distribution are subjected to greater measurement errors than the AOD and cloud microphysical part of the retrieval, which potentially leads to errors with SSA (as evidenced by the larger error bars with SSA). In contrast, the SSFR retrieval could be considered a somewhat more "direct" derivation of SSA, in that it retrieves SSA directly and individually for each wavelength on the basis of absorbed irradiance and 4STAR-measured AODs alone, with minimal constraints and assumptions on aerosol (e.g., size distribution, shape, and mixing state). At the same time, we note that the wavelength dependence of SSA and asymmetry parameters which are retrieved from the SSFR measurements are not necessarily consistent with a physically realizable microphysical model, which may well be a drawback in trying to generalize these retrievals for related radiative transfer calculations - though particularly in complex combined aerosol-cloud scenes such as these, the positives may outweigh the potential negative aspects of this re-

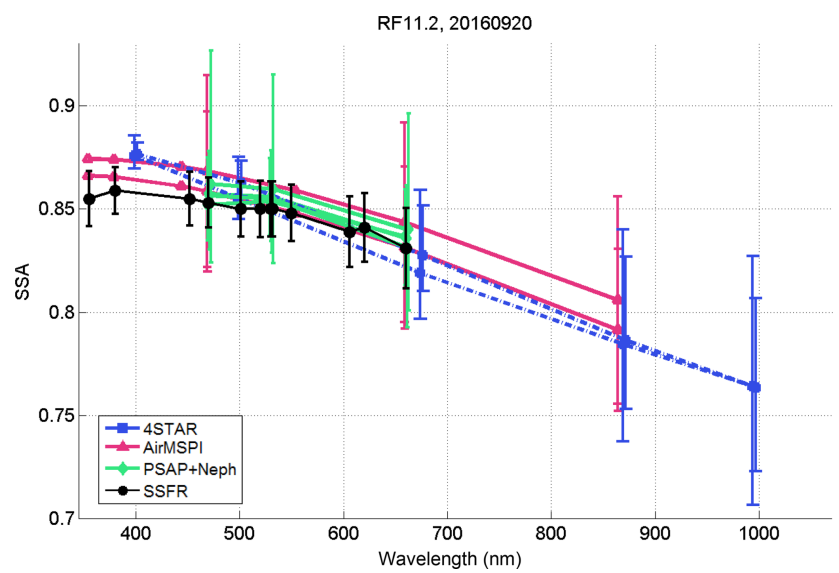

Figure 6. As in Fig. 4 but showing spectral SSA for the ORACLES instruments operating on 20 September 2016: 4STAR sky scan retrievals (blue squares); AirMSPI retrievals (pink triangles); SSFR square spiral (black circles); and profile-averaged extinctionweighted SSA from the PSAP + neph (green diamonds). This case was centered at approximately $16.7^{\circ} \mathrm{S}, 9^{\circ} \mathrm{E}$, and sampled from 10:45 to $12: 15$ UTC. Note that for clarity, AirMSPI uncertainties are only reported for the three wavelengths input into the polarized retrieval algorithm (Sect. 2.1.2).

trieval method. Regardless of the potential uncertainties of each method, the fact that retrievals using such different measurement approaches agree so well is encouraging.

Figure 7 shows the spectral optical depths for this same case, by instrument. Note that the AOD input to the SSFR retrieval $\left(\mathrm{AOD}_{400 \mathrm{~nm}}=0.78\right)$ is obtained by $4 \mathrm{STAR}$ at the location of the square spiral, while the AODs reported as 4STAR (Fig. 7b) are from the times of the sky scans on the southbound leg directly preceding the spiral, as described above. The first scan $\left(\mathrm{AOD}_{400 \mathrm{~nm}}=1.05\right)$ was approximately $50 \mathrm{~km}$ from the square spiral location, which accounts for the difference in AOD between the two. The second scan $\left(\mathrm{AOD}_{400 \mathrm{~nm}}=1.24\right)$ is approximately $110 \mathrm{~km}$ from the spiral location ( $8 \mathrm{~min}$ after the previous scan in flight time). While this is on the higher end of our desired spatial spread, we show both scans here to show the good agreement in the spectral shape of the aerosol optical properties (i.e., spectral SSA and Angström exponents; Figs. 6 and 7) between the two retrievals even with differences in aerosol column loading (AOD and, consequently, AAOD) (Fig. 7). Indeed, the Angström exponents for this case vary within only 0.2 for all five instruments, which is better agreement than the three instruments shown in the previous case. The outlier again is the 4STAR AAE values of approximately 0.9 , lower than any other retrieval. This is discussed in more detail in the following section. 


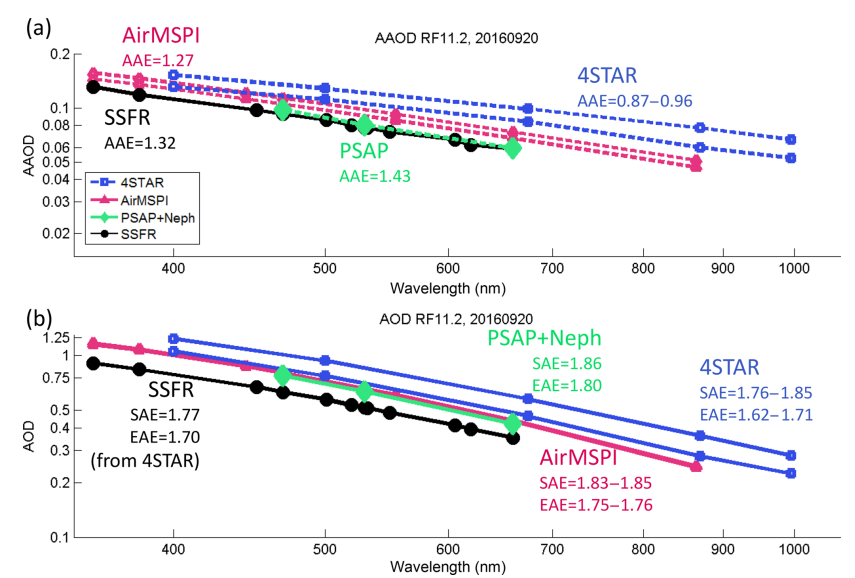

Figure 7. As in Fig. 5, (a) AAOD and (b) AOD versus wavelength (both on log-log scales) for the case on 20 September for 4STAR, AirMSPI, SSFR, and PSAP + neph. The PSAP + neph optical depths are calculated from a $100 \mathrm{~m}$ bin average profile of nephelometer scattering and PSAP absorption, and integrated over the vertical column. This case had a full profile from $367 \mathrm{~m}$ to $7.1 \mathrm{~km}$ (shown) and additional partial profiles which appear in Fig. 6. Note that SSFR uses 4STAR AOD as input; this coincident AOD is labeled as SSFR for clarity; thus, the differences between these three AOD spectra are due to spatial variability in the total amount of aerosol loading, likely due to variations in plume-top height $(\sim 5.5-$ $6 \mathrm{~km}$ ) as observed by HSRL-2.

\subsection{Campaign-wide ORACLES-2016 instrument comparisons}

The two cases shown in the previous section are intended to give an idea of the range of observed cases in clear and cloudy skies, while allowing comparison with available RSP and SSFR retrievals. Next, we broaden scope to consider instrument comparisons for the campaign as a whole. We focus on in situ versus 4STAR comparisons, as these are the two methods with enough coincident measurements to allow for a statistical examination. We also include a more limited number of comparisons using AirMSPI data where available.

Figure 8 shows scatter plots of several parameters (SSA, EAE, SAE, and AAE) as measured by sets of two instrument pairs - 4STAR versus in situ versus AirMSPI - across the full set of comparison cases. As one case may have multiple retrievals (i.e., multiple vertical profiles, sky scans, and/or sweeps), the case-average data are indicated by filled black markers. All data (i.e., multiple individual retrievals included in a comparison case) are shown as small $\times$ marks, with grey lines indicating the range of retrievals within a given case. The top row of Fig. 8 shows scatter plots of $\mathrm{SSA}_{530 \mathrm{~nm}}$ reported by 4STAR, in situ, and AirMSPI for the aggregation of all comparison cases where two of the three can be compared (Table 2). 4STAR SSA is generally lower than the in situ SSA (Fig. 8a), and AirMSPI SSA is higher than both 4STAR or in situ (Fig. 8b, c). While 4STAR and in situ gen- erally track one another, the relationship is not statistically significant $(R=0.23, p=0.33)$. Similar results are seen for EAE and SAE (Fig. 8d-i), though the correlation in SAE between 4STAR and in situ is the only combination that could be considered robust: $R_{\mathrm{SAE}}=0.66$ with $p<0.01$, whereas $R_{\mathrm{EAE}}=0.44$ and $p=0.06$.

It is interesting to note that the one outlier in Fig. 8d and $\mathrm{g}$ (low 4STAR SAE and EAE) is the case from 12 September described earlier (Figs. 4 and 5), where the two 4STAR sky scans at lower altitude (i.e., immediately before the in situ profile) are those which result in the very low AE values which depress the average for that case. As seen in Figs. 4 and 5, there is no such divergence in $\mathrm{SSA}_{530 \mathrm{~nm}}$ or AAE for this case. We also note that the correlation described above between 4STAR and in situ EAE disappears when this outlier case is excluded.

In contrast to the other parameters, the 4STAR AAE shows, if anything, a negative relationship with in situ derived AAE (Fig. 8j), though this relationship is again not statistically significant $\left(R_{\mathrm{AAE}}=-0.37, p=0.12\right)$. We additionally note that the 4STAR-reported AAE values are low in general, often $<1$, and are split into two populations: one in fairly good agreement with in situ $(R=0.50, p=0.08)$ and one substantially offset to lower 4STAR AAEs relative to in situ, with a similar but less robust correlation $(R=0.59$, $p=0.22$ ). As a whole, the full 4STAR AAE data set is negatively correlated with the in situ values. The relationships between AAE from AirMSPI and either of the other two instruments (Fig. 8k, l) are also not statistically significant, due to the small range in AAE values retrieved from AirMSPI. The variability in AAE for aerosol within a given case (date and location) is also often quite large; this, combined with the lack of correlation between instruments, may simply reflect a higher uncertainty in derived absorption Ångström exponents from all methods.

As the 4STAR retrievals frequently show AAE values less than 1, this bears some discussion. Notably, Bahadur et al. (2012) also derived very low values of AAE (as low as 0.55 for pure BC) using the same AERONET retrieval algorithm. While some previous observational studies have allowed for AAE values less than 1 (e.g., Bergstrom et al., 2007; Lack et al., 2008), these results may be due to measurement artifacts or instrument uncertainties. While pure BC is typically considered to have an AAE of 1, theoretical and practical studies have shown this to vary based on particle size (e.g., Lack and Cappa, 2010; Wang et al., 2016) and may be either higher or lower than 1, particularly when various coatings are applied (e.g., Gyawali et al., 2009). However, brown carbon typically has AAE greater than that of BC, and the 4STAR $\mathrm{AAE}$ values are in the lower range of the values expected from theory even for pure BC (e.g., Schnaiter et al., 2005; Gyawali et al., 2009; Lack and Cappa, 2010). Thus, values of AAE for a mixed aerosol (smoke) that are less than 1 (for the wavelength range $440-675 \mathrm{~nm}$ ) may be considered suspect in that they run counter to many observations of ambient- 
aerosol (i.e., black carbon plus brown carbon) AAE, including in this region (Bergstrom et al., 2007). As such, these results should be treated with caution. Another factor to consider is the compounding uncertainties (i.e., as the slope of another derived property) inherent in the derivation of AAE by any method. As an example, the simple propagation of the AirMSPI AOD uncertainties of 0.03 in the visible range and 0.05-0.06 in the UV, and SSA retrieval error of 0.02-0.04 give an uncertainty in AAE measurements of approximately 0.4-0.5, well encompassing the difference between this instrument and either 4STAR or in situ. While 4STAR SSA uncertainties are more variable from case to case, some typical values (wavelength-dependent AOD and SSA uncertainties of $0.01-0.03$ and $0.01-0.04$, respectively) give a similar level of AAE uncertainty.

Figure 9 shows the difference in Ångström exponents (AAE, top row; SAE, bottom row) from the in situ measurements versus from 4STAR retrievals as a function of AAE (top row) and SAE (bottom row) for each instrument, and as a function of AAOD (for AAE) or AOD (for SAE). This allows for visualization of the level of agreement between the two methods as a function of the retrieved properties themselves and amount of aerosol loading.

The first two panels (Fig. 9a, b) show the dependence of the difference between AAE from in situ and 4STAR measurements as a function of AAE. This shows a fairly strong correlation between higher values of in situ AAE and greater differences (in situ minus 4STAR), with the expected opposite correlation observed for high 4STAR AAE versus AAE difference $(R=0.76$ and -0.89 , respectively, both $p<0.001)$. In other words, as AAE increases as measured by the in situ observations, the difference between the in situ and 4STAR AAEs increases - and higher in situ AAE values correspond with lower 4STAR AAE values, resulting in a greater difference between the two (Fig. 8j). The fact that the difference between the two is correlated with each suggests that this is not a clear case of one versus the other driving the large differences.

A weaker correlation of the same sign is observed for the difference in SAE and in situ- or 4STAR-measured SAE ( $R=0.48$ and -0.57 , respectively, both $p<0.001$, though the latter shrinks to $R=-0.22, p=0.04$ when removing the outlier shown) (Fig. 9d, e). While there is a weak $(R=0.50)$ but significant correlation $(p<0.001)$ between AAOD and the AAE difference between the two instruments (Fig. 9c), there appears to be no correlation between total aerosol loading (4STAR AOD) and SAE (Fig. 9f). This suggests that total aerosol loading does not affect the instrument agreement for this parameter, but higher values of absorbing aerosol may bias one or both of the instruments; while the filterbased PSAP instruments have well-known artifacts, there is also a weak negative correlation between $\mathrm{AAOD}_{530 \mathrm{~nm}}$ and $\mathrm{AAE}_{4 \operatorname{STAR}}(R=-0.34, p=0.001)$.

Figure 9 additionally shows the wavelength dependence in $\mathrm{AE}$ calculated for different wavelength ranges (colored markers). This illustrates the difference in AE values (AAE and SAE), particularly from the in situ instruments, which may result simply from altering the wavelengths used in their calculations, without significantly altering the wavelength limits. Bergstrom et al. (2007) showed a similar dependence of the calculated AAEs on the wavelengths used. For example, here, we see a distinct spread between the AAE calculated between the two shortest wavelengths (470 to $530 \mathrm{~nm}$; blue circles) and the two longest wavelengths (530 to $660 \mathrm{~nm}$; red triangles), with the former showing the largest difference between in situ and 4STAR as well as the largest values of in situ AAEs. The same is true for the in situ SAE, except with opposite sign: the SAEs calculated using the longest wavelengths have the highest values. The differences in AAE are largely positive regardless of the wavelengths used: in other words, in situ gives higher AAE than 4STAR, with the 4STAR AAE values anomalously low relative to previous estimates of AAE, as discussed earlier. For SAE (and also EAE), the differences are more symmetrical, with negative values (4STAR greater than in situ) for the shortest wavelengths and positive values (in situ greater than 4STAR) for the longest wavelengths. It is also worth noting that the difference between values for these two wavelength ranges (shorter minus longer) is between 0.1 and 0.4 for $\mathrm{AAE}$ and up to -0.5 for SAE from in situ and up to -0.3 for AAE and SAE from 4STAR, which is a substantial range, given that the range in instrument AEs over all the comparison cases were largely within 0.5 of one another. The significant variability seen here between values simply calculated from different wavelengths again suggests caution not to overinterpret Ångström exponents, particularly those calculated using only two wavelengths.

In contrast to the $\mathrm{AE}$ results, there is no dependence in the differences in mid-visible SSAs between the in situ measurements and 4STAR retrievals: for $\mathrm{AOD}_{470 \mathrm{~nm}}>$ 0.4 and $\mathrm{AAOD}_{470 \mathrm{~nm}}>0.05$ (Fig. 10), the differences are within \pm 0.03 , within the expected uncertainties. At lower AOD/AAOD, the differences are more pronounced, tending to higher values for 4STAR at lower loadings. This is consistent with the minimum AOD threshold value defined in the AERONET QC procedure $\left(\mathrm{AOD}_{440 \mathrm{~nm}}>0.4\right)$.

\section{Discussion}

\subsection{Campaign-wide measurements of SSA from multiple instruments}

We now turn to the full set of SSA data from ORACLES2016. Figure 11a shows campaign-wide averages of SSA for 4STAR, AirMSPI, and PSAP + nephelometer. As these are campaign-wide values, they are not strictly comparable to one another; for example, the spatial coverage of the AirMSPI retrievals is larger than the other two instruments, due to the greater spatial range of the ER-2 versus P-3 flights 


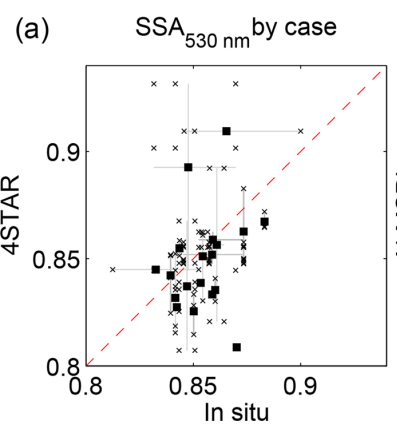

(b) $\quad \mathrm{SSA}_{530 \mathrm{~nm}}$ by case

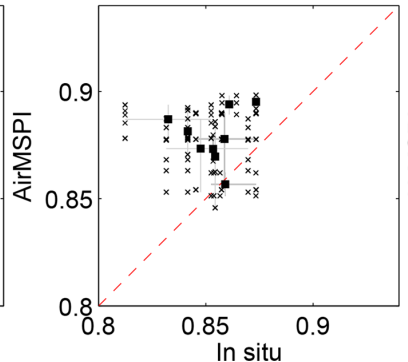

(d)

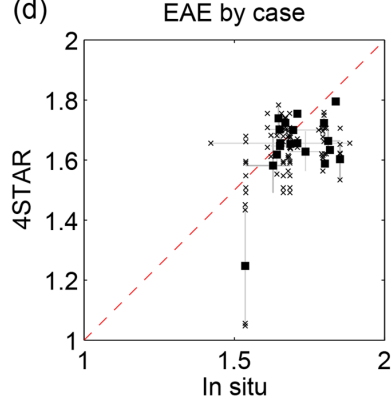

(g)
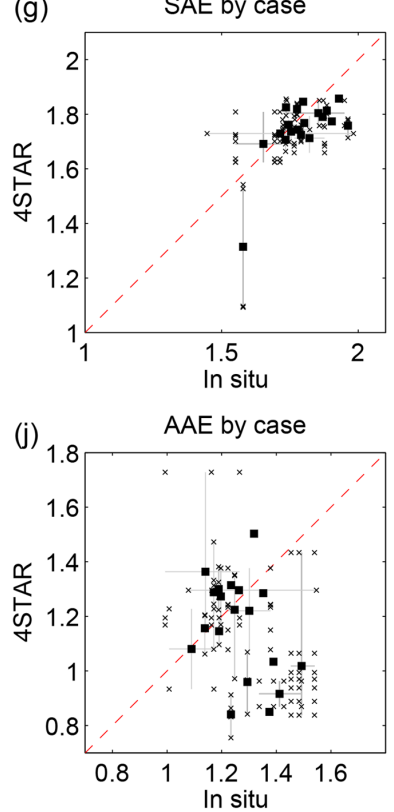

(e)

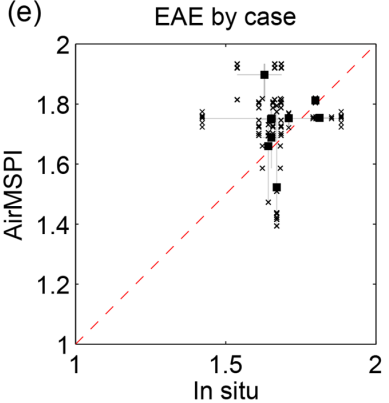

(h)

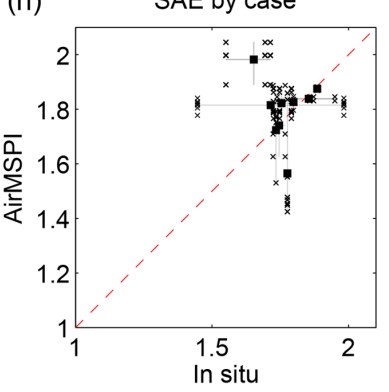

(k)

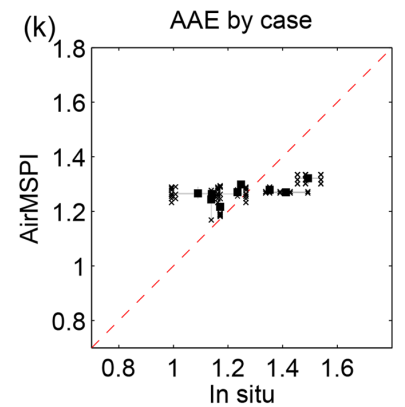

(c) $\mathrm{SSA}_{530 \mathrm{~nm}}$ by case

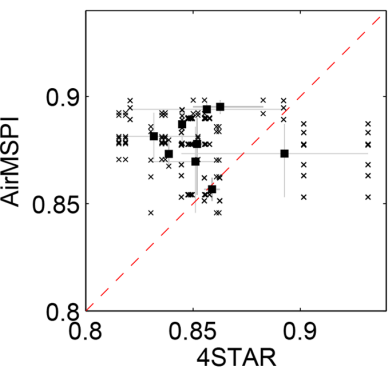

(f)

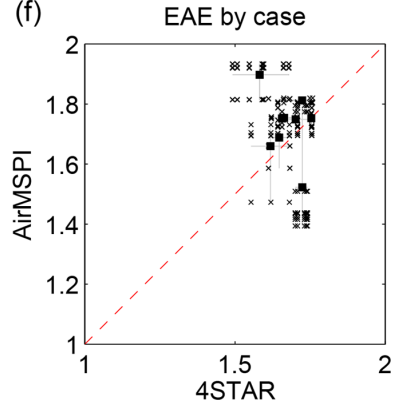

(i)

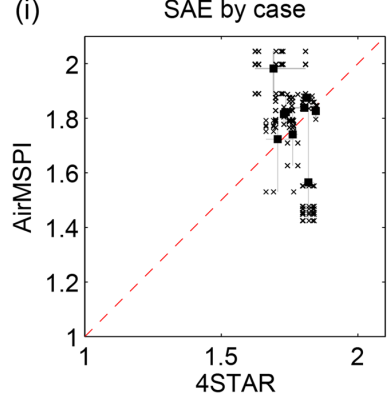

(I)

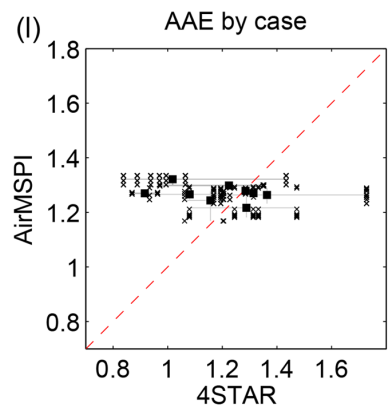

$-1: 1$ line $\times$ All data - Case average

Figure 8. (Top row) $\mathrm{SSA}_{530 \mathrm{~nm}}$, (second row) EAE, (third row) SAE, and (bottom row) AAE for (left column) 4STAR versus in situ measurements (middle column) AirMSPI versus in situ measurements, and (right column) AirMSPI versus 4STAR measurements, for all comparison cases with valid coincident observations. All individual retrievals are shown by grey $\times$ marks; for cases with multiple retrievals from a single instrument, the average value and range for a given case is shown by a black circle with whiskers.

(Fig. 11a, inset). Also, the AirMSPI data considered here are from 6 flight days, compared with 13 flight days for 4STAR and 14 flight days for the in situ measurements. In addition, the P-3-based measurements (PSAP + neph and 4STAR) were able to sample more coastal aerosol, which may be more influenced by variability in local aerosol sources and thus composition (compared with far-from-coast flights which would sample the upper-level plume of more uniform origin). Further discussion of the 4STAR-observed temporal and spatial variability of aerosol loading and size in ORACLES-2016 may be found in LeBlanc et al. (2019), and comprehensive discussion of the observations as they com- 

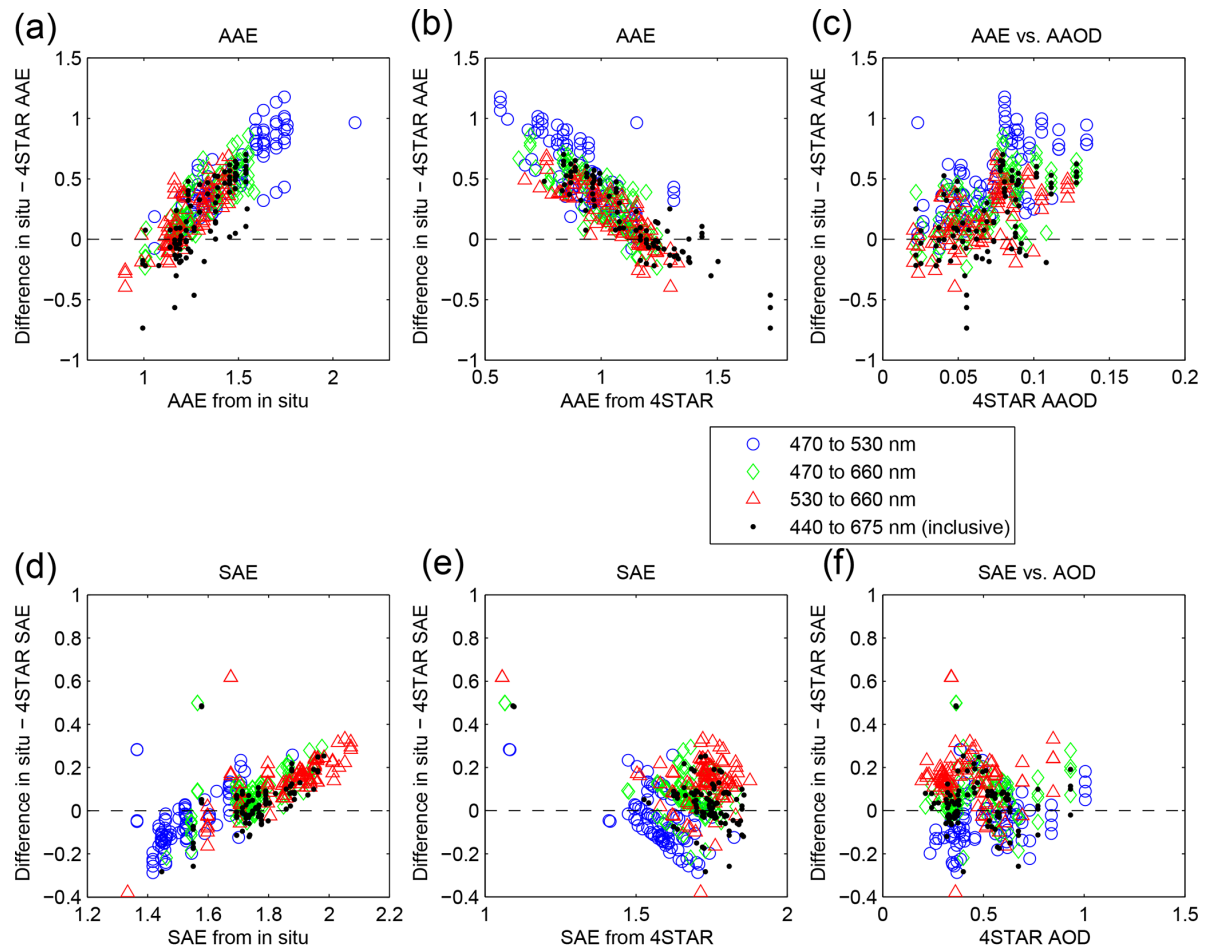

Figure 9. Difference between AAE measured in situ versus retrieved from 4STAR (in situ - 4STAR) as a function of (a) in situ AAE, (b) 4STAR AAE, and (c) 4STAR AAOD. The bottom panels show the same but for SAE differences versus (d) in situ SAE, (e) 4STAR SAE, and (f) 4STAR AOD. Note that multiple individual points for one instrument (profiles or sky scans) may be shown for comparison cases which included more than one sample per instrument (i.e., $\times$ marks in Fig. 8). This is an indication of the variability within a specific case.

pare with model outputs will be included in a later work. Interestingly, both the offset and the sign of the difference between 4STAR and in situ measurements are similar to the results of Schafer et al. (2014), who found AERONETderived SSAs were on average 0.011 lower than in situ (PSAP + nephelometer) values for flights over the eastern US.

Figure 11a also shows that the variability of the SSA from the P-3-based measurements (4STAR and in situ) is fairly similar in the mid-visible range: roughly 0.025 between the first and third quartiles for 4STAR versus 0.028 for the in situ measurements. At longer wavelengths ( 875 and $995 \mathrm{~nm})$, the 4STAR variability approximately doubles; the uncertainty for individual 4STAR sky scans is also higher at these longer wavelengths. In situ data are not available at these wavelengths.

Figure $11 \mathrm{~b}$ shows the ORACLES spectral SSA values compared with those from previous studies, as presented in Fig. 1. SSA from the three ORACLES measurements are within the range of previous observations of SSA, with the difference in SSA between the SAFARI "fresh" versus "aged" plume (Haywood et al., 2003) bounding these observations. It is important to note that this "fresh" plume is based on a single flight directly over a terrestrial emission source (13 September 2000), whereas the "aged" values are the mean values from the remaining eight flights, ostensibly sampling aerosol at least 2-3 d old (Haywood et al., 2003, their Table 2). While the "aged" SAFARI values should be more comparable to the expected age of ORACLES-sampled aerosol from oceanic overflights (compared with the "fresh" plume), in-field experience with aerosol model forecasts indicated the age of ORACLES-sampled free-tropospheric aerosols were typically older than $4 \mathrm{~d}$ (Dobracki et al., 2019). Both of these ORACLES and SAFARI values are based on in situ measurements (PSAP + neph), whereas the SAFARI result shown in Russell et al. (2010) (and also described in Bergstrom et al., 2003) is from an SSFR-centered retrieval combined with data from a precursor to 4STAR, AATS-14 (the Ames Airborne Tracking Sun photometer at 14 wavelengths) similar to the retrieval used in this paper. The retrieval is from a radiation wall within a single flight (6 September 2000). By way of comparison, flightaverage SSA from the PSAP + neph measurements on that same flight was given as $0.87,0.86$, and 0.83 at 450,550 , and $700 \mathrm{~nm}$ (Haywood et al., 2003), somewhat lower than the "aged" average of $0.91,0.90$, and 0.87 and only 0.01 lower than the SSFR values for the same flight. In the same work, SSA was also derived using filter measurements integrated over size distributions measured by a Passive Cavity Aerosol Spectrometer Probe (PCASP); the PCASP-derived 

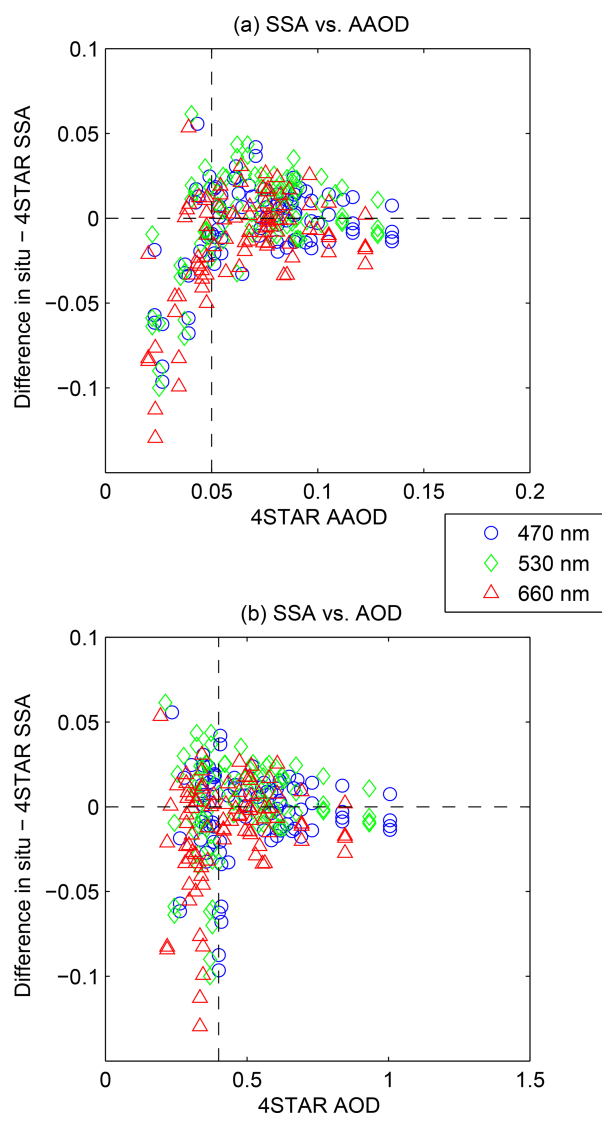

Figure 10. The difference between SSA measured in situ versus retrieved from 4STAR (in situ - 4STAR) as a function of 4STAR (a) AAOD and (b) AOD, respectively.

values for this particular flight are given as $0.92,0.89$, and 0.87 , closer to the high end of the range. Thus, with the available data, it is difficult to definitively say whether the variability among previous measurement methods is predominantly due to systemic variability between different measurement methods or whether it is purely a function of natural variability - from either seasonal changes in emission factors, evolution in aerosol properties after emission, or spatial variability such as the SSA dependence with altitude as seen in ORACLES.

\subsection{Impacts of humidification on aerosols}

In this work, we have presented SSA as calculated from in situ measurements of scattering (from a nephelometer) and absorption (from a PSAP and a PTI); all are for aerosol dried to $\mathrm{RH}<40 \%$. It is well known that an increase in $\mathrm{RH}$ will result in an increase in scattering, which, if it is the sole consequence of the humidification, will act to increase the SSA. However, humidification of aerosol will impact both scattering and absorption, likely not to the same degree, and thus will affect the resulting SSA, potentially in competing direc-

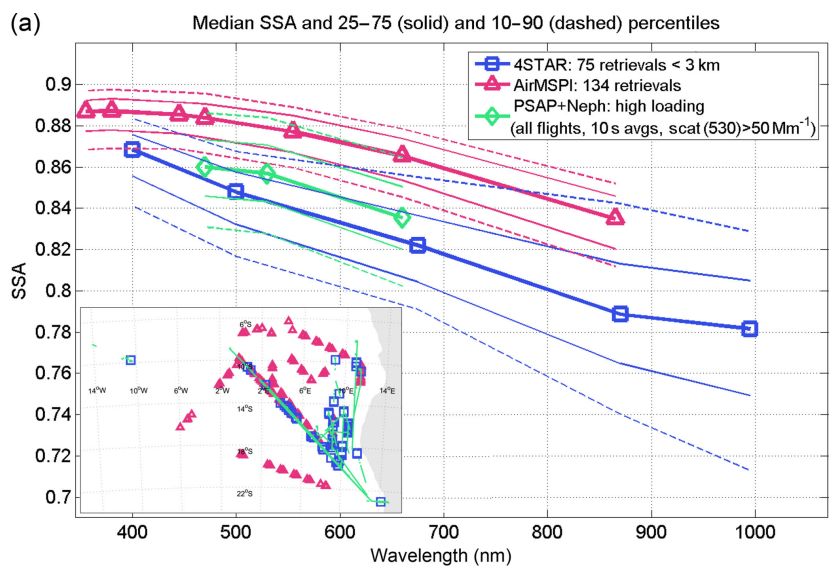

(b) SSA values from previous studies compared with ORACLES instrument averages

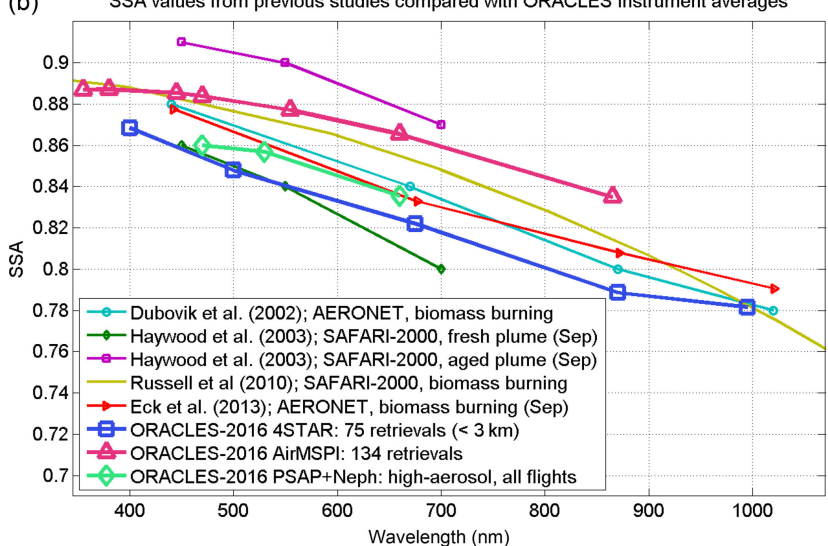

Figure 11. (a) SSA from all measurements/retrievals over ORACLES-2016, from 4STAR, AirMSPI, and the nephelometer and PSAP in situ data. The campaign-wide median is indicated by the thick solid line, 25 th-75th percentiles are indicated by thin solid lines, and 10th-90th percentiles are indicated by the dashed lines. Note that the medians of the different instruments are not strictly comparable, as the campaign-wide averages are calculated using more data than just the coincident cases. The inset shows the spatial distribution (latitude/longitude) of measurements by the three instruments. (b) The median SSA by instrument as shown in panel (a) compared with SSA from previous studies in this same region (Fig. 1).

tions. For this reason, we have presented in situ measurements as measured (i.e., dried) in this present work.

Aerosol absorption is likely affected by humidification, but the magnitude of this effect is much less well understood, due in large part to the difficulty in measuring humidified absorption directly (e.g., Arnott et al., 2003). However, several studies have attempted to address this question. One theory-based study using a BC core/shell model (Redemann et al., 2001) found that in terms of the aerosol absorption, the absorption enhancement at RH of $80 \%$ was approximately a factor of 1.1, resulting in a decrease in SSA of 0.02 at $550 \mathrm{~nm}$. They also found that the degree to which humidification enhanced the absorption is dependent on the aerosol size distribution, with absorption enhancement as 
high as a factor of 1.75 for certain size and humidity conditions (up to $99.5 \%$ ). In a later lab-based study measuring total extinction and nephelometer-measured scattering, Brem et al. (2012) found enhancement of absorption from biomassbased organic carbon (OC) aerosol to be significant at 467 and $530 \mathrm{~nm}$ for $\mathrm{RH}>85 \%$ (the $660 \mathrm{~nm}$ data were within the instrument noise). Between $32 \%$ and $95 \% \mathrm{RH}$, the absorption at 467 and $530 \mathrm{~nm}$ increased by factors of $2.2 \pm 0.7$ and $2.7 \pm 1.2$, greater than that found by Redemann et al. (2001); combined with the observed enhancement in scattering, this corresponded to a change in SSA on the order of 0.06 for $470 \mathrm{~nm}$ and 0.03 for $530 \mathrm{~nm}$, though the authors acknowledge that their method is subject to large uncertainties. We further note that the majority of studies considering the effect of humidification on aerosol absorption (and scattering) consider the more extreme values of $\mathrm{RH} \geq 85 \%$ or higher, which was a rare occurrence in the BB plume sampled in ORACLES-2016 (observed plume RH was a maximum of $80 \%$ and often lower, as described in earlier sections). The magnitude of these effects are thus likely to be some factor smaller than the values reported in the literature. The unequal enhancement factors at different wavelengths suggest that the absorption Ångström exponents would also be affected, adding to the uncertainty in this parameter. As the effects of humidification on absorption have been seen to depend on aerosol age and composition (i.e., hydrophobic versus hydrophilic; coated versus uncoated aerosol) (e.g., Mikhailov et al., 2006; Zhang et al., 2008), and even result in a decrease in absorption with increasing humidity (by $20 \%$ for an $\mathrm{RH}$ of $80 \%$ in Lewis et al., 2009), the question of the magnitude of RH impacts on absorption remains an open one.

Due to this uncertainty in the cumulative effects of humidification, an open question is how humidification affects the study at hand, given that we perform comparisons between in situ SSA values from measurements at low RH and the SSA values from the retrievals (SSFR, 4STAR, AirMSPI, RSP) which are made at ambient RH. While there was persistent elevated relative humidity within the biomass burning plume relative to the free troposphere absent the plume, in ORACLES-2016, approximately half of the time where aerosol concentrations were high $\left(\sigma_{\text {scat }, 530 \mathrm{~nm}}>50 \mathrm{Mm}^{-1}\right)-$ i.e., when the P-3 was in the plume - the measured relative humidity was $<40 \%$ (the "dry" threshold), and an additional $30 \%$ of the time $\mathrm{RH}$ was in the range $40 \%<\mathrm{RH}<60 \%$. While we cannot make a reasonable estimate of the effects of humidification on absorption, we can estimate how much it might be affecting scattering, and bound the upper limit on SSA accordingly (i.e., assuming zero effect on absorption). Based on a campaign-average scattering enhancement of 1.4 for a plume $\mathrm{RH}$ of $80 \%$, and making the coarse assumption of no effect of humidity on absorption, we would expect the maximum impact of typical humidification on scattering to increase instantaneous SSA (at $530 \mathrm{~nm}$ ) by a maximum of $0.03-0.05$. However, in reality, this value will be lower, first due to the variability of RH with altitude as described in
Sect. 3.1, which will have a lesser impact at lower altitudes and thus on the column-averaged values considered here, and second due to the competing impacts of humidification on absorption as described above, which likely have the opposite effect of lowering SSA. Due to the high uncertainties surrounding these competing effects, we leave it to a future work to provide more a detailed quantification of humidification effects on aerosol absorption and the SEA biomass burning SSA.

\section{Conclusions}

In this work, we present new measurements of absorbing aerosol optical properties over the southeast Atlantic Ocean, a region with a significant and persistent seasonal biomass burning plume overlying stratocumulus clouds and which, up to now, has had a dearth of observations. For specific comparison cases, the retrievals from remote sensing (4STAR, AirMSPI, RSP, and SSFR) and in situ (derived from PSAP, nephelometer, and PTI) agree within given uncertainty ranges, though with some indications of systematic differences between the different methods. Specifically, the modified AERONET retrievals applied to 4STAR data typically produce the lowest SSA, while the AirMSPI polarized retrieval generally yields the highest SSA. There are a number of potential causes behind these patterns, including the different information content in the measurements from different instruments (e.g., the AirMSPI polarized radiances are less sensitive to aerosol refractive index versus aerosol loading), viewing geometry (e.g., upward-looking versus downward-looking observations may have different information using transmitted versus reflected light), retrieval assumptions (e.g., aerosol model used, a priori assumptions, smoothness constraints), as well as simply the degree of coincidence which was achievable for these comparison cases. Correlations between individual instruments over an aggregate of cases (using between 9 and 19 available comparison cases for different instrument pairs) were not significant in most cases, with the exception of a weak positive correlation between 4STAR- and in situ-derived SAE. AAE is the least certain of the retrieved absorption properties, as it shows a weak, yet negative, correlation between the two instruments considered, with a significant portion of the data reporting AAE values less than 1. Again, we can only speculate as to the causes of the differences; each retrieval comes with a unique set of a priori assumptions and slightly different measurement inputs, which may explain the small range in AAE values from AirMSPI and the generally lower AAEs from 4STAR. Finally, we note that this work represents a starting point for many subsequent ORACLES-based analyses. These will include a more detailed comparison of the methodological differences between different instrument algorithms; a discussion of the SSA spatial variability and its 
potential causes; and an exploration of the effect of humidification on aerosol absorption.

In terms of the ORACLES-2016 dataset as a whole, we find median SSAs from 4STAR to be $0.87,0.85,0.82,0.79$, and 0.78 at 400, 500, 675, 870, and $995 \mathrm{~nm}$; from AirMSPI to be $0.88,0.87$, and 0.84 at the retrieved wavelengths of 470 , 660 , and $865 \mathrm{~nm}$; and from in situ measurements to be 0.86 , 0.86 , and 0.84 at 470,530 , and $660 \mathrm{~nm}$. Campaign-wide data variability (5th-95th percentiles) is roughly equivalent for 4STAR and in situ measurements in the mid-visible range $( \pm 0.03)$ and is greater at the longer 4STAR wavelengths $( \pm 0.05$ at $870 \mathrm{~nm})$. The AirMSPI data exhibit less variability at all wavelengths ( \pm 0.015 at $470 \mathrm{~nm}$ and \pm 0.02 at $865 \mathrm{~nm})$. While these are not directly comparable to one another due to differences in spatial and temporal sampling of the different instruments, they give an indication of the best estimate and range of biomass burning SSAs over the southeast Atlantic Ocean. The range of SSA values reported between different instruments during ORACLES is consistent with the range reported among previous observational studies over this region but slightly higher than those reported downwind on Ascension Island (Zuidema et al., 2018). In Sect. 1.2, we discussed the radiative forcing implications of SSA; finally, we note that the range of SSAs observed from each instrument is of the magnitude expected to change local direct radiative effects by $10-20 \mathrm{~W} \mathrm{~m}^{-2}$ (SSA \pm 0.03$)$, which may give an indication of the impact of the results. Any studies which rely on a prescribed set of aerosol properties - such as SSA - as input should thus consider a realistic spatiotemporal distribution of aerosol optical properties in order to best capture the reality of the aerosol conditions over this region. It is important to take into account the impacts of the spatial variability and uncertainty from a given instrument, as they may affect resulting determinations of radiative effects of biomass burning aerosols.
Code and data availability. The data used in this paper are publicly available at https://dx.doi.org/10.5067/ Suborbital/ORACLES/P3/2016_V1 (ORACLES Science Team, 2019a) for the P-3 data (4STAR, in situ, SSFR) and at https://dx.doi.org/10.5067/Suborbital/ORACLES/ER2/2016_V1 (ORACLES Science Team, 2019b) for ER-2 data (RSP). All AirMSPI L1 data are available at https://dx.doi.org/10.5067/ AIRCRAFT/ORACLES/RADIANCE/AirMSPI (AirMSPI Science Team, 2019), and the AirMSPI above-cloud aerosol (ACA) retrieval data used here may be found at https://eosweb.larc. nasa.gov/project/airmspi/preliminary-airmspi-datasets (following the link under Xu_etal_JGR2018_ACA_AirMSPI, last access: 9 July 2019). The codes used in processing 4STAR sky scan data may be found at https://doi.org/10.5281/zenodo.1492912 (4STAR Team, 2019). 


\section{Appendix A: Additional discussion of in situ measurements}

\section{A1 PSAP Virkkula corrections}

As discussed in the above text, the PSAP absorption corrections were applied as given in Virkkula (2010). Corrections of this nature must be applied due to the limitations inherent in filter-based measurements. Virkkula (2010) gives both wavelength-specific $(470,530$, and $660 \mathrm{~nm})$ corrections and a wavelength-averaged correction (his Table 1). We choose the latter due to the discovery during the LASIC campaign (Zuidema et al., 2018) that using wavelength-specific values resulted in an unphysical jump in AAE upon changing of the filters. The difference between the absorption coefficients, and the resulting SSA, for the two methods is shown in Fig. A1. Note that the wavelength-specific values generally show $\mathrm{SSA}_{470}<\mathrm{SSA}_{530}$ due to higher reported absorption at $470 \mathrm{~nm}$. Figure A2 highlights the difference in wavelengthaveraged versus wavelength-specific SSA for the individual profiles in the 20 September case, as discussed in the text. Note that for the analysis below in Sect. A2, the Virkkula corrections likely do not contribute to the observed differences between PTI and PSAP, as the absorption at the $530 \mathrm{~nm}$ wavelength is less impacted by the choice of correction factor.

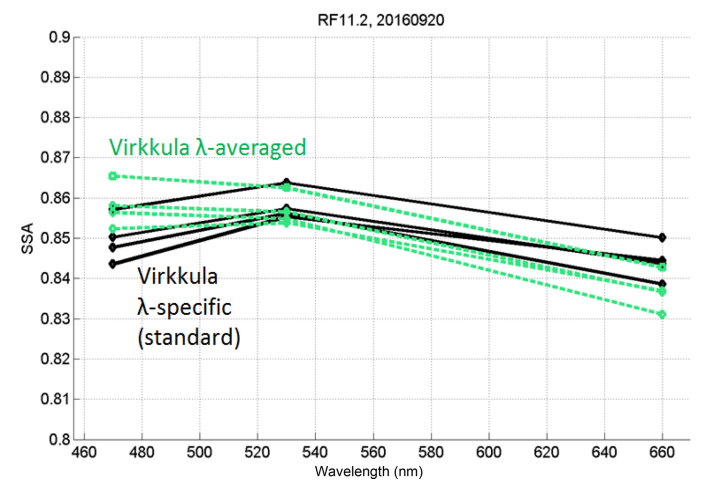

Figure A2. Profile-averaged extinction-weighted SSA for the case study shown on 20 September 2016. The impact on the $470 \mathrm{~nm}$ SSA (and consequently, the spectral shape) is the most notable difference. We attribute this spectral shape to the stronger increase in aerosol absorption at the shortest wavelength - while scattering also increases, it exhibits a smaller wavelength dependence than does absorption (Fig. A1).
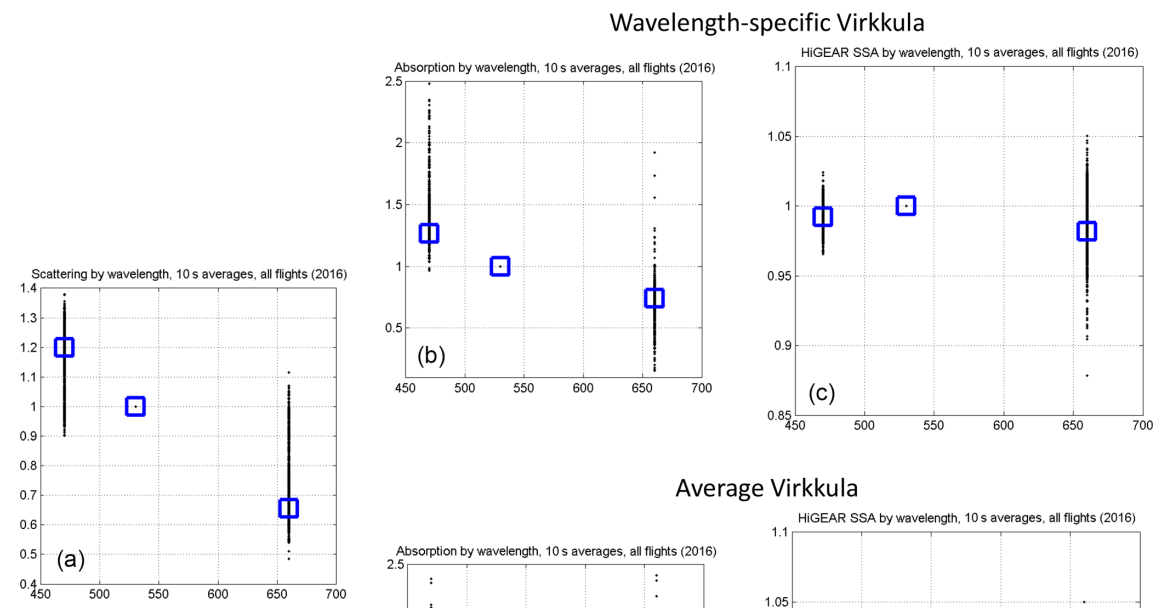

Average Virkkula
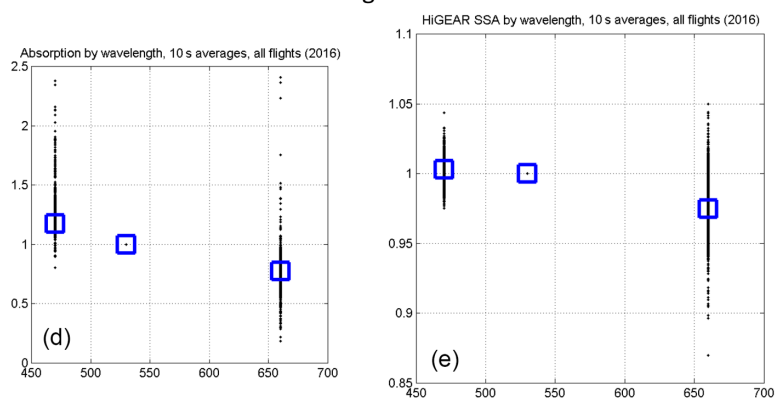

Figure A1. Normalized nephelometer scattering (a), PSAP absorption (b, d), and resulting SSA (c, e) for 470, 530, and 660 nm, using wavelength-specific (b, c) and wavelength-averaged (d, e) Virkkula corrections. Values are normalized to highlight the relative spectral shape. Blue squares indicated the median of all observations (black). Note that while the scattering and absorption both exhibit an overall decrease with wavelength, the much sharper decrease in absorption results in a small maximum in SSA at $530 \mathrm{~nm}$ under the standard wavelength-dependent Virkkula corrections applied to the PSAP. This spectral feature disappears in the average Virkkula case. 


\section{A2 Comparison of absorption from in situ instruments}

As ORACLES-2016 had two measures of aerosol absorption available, we think it useful to discuss these two in situ instruments as they compare to one another, though with an eye to the technical difficulties of the PTI in that year's deployment. Figure A3 shows $30 \mathrm{~s}$ averages of absorption from the PTI and from the PSAP for all available coincident data for the five flights with the PTI operational (flights on 10, $12,14,20$, and 24 September). The effect of the high noise floor applied to the reported PTI values is evident in the data variability, and the PTI absorption is seen to be generally lower than PSAP absorption over all days, consequently with a smaller dynamic range: 5th-95th percentiles of 20.3 to $28.8 \mathrm{Mm}^{-1}$ (median $22.8 \mathrm{Mm}^{-1}$ ) for PTI compared with 21.8 to $40.9 \mathrm{Mm}^{-1}$ (median $26.6 \mathrm{Mm}^{-1}$ ) for the coincident PSAP measurements. The generally lower PTI absorption could be due to the mechanical difficulties in the 2016 deployment, as was described in Sect. 2.1.4. From a physical perspective, the difference between the two instruments may additionally be enhanced by an artificially low-biased PTI signal driven by latent heat of evaporation under highhumidity aerosol conditions. On the part of the PSAP measurement, the multiple scattering from this filter-based measurement could potentially give an artificially high-biased PSAP signal. Improvements in the PTI instrument design for the 2018 deployment will likely facilitate better comparative analysis between the two measurement techniques at a future date.

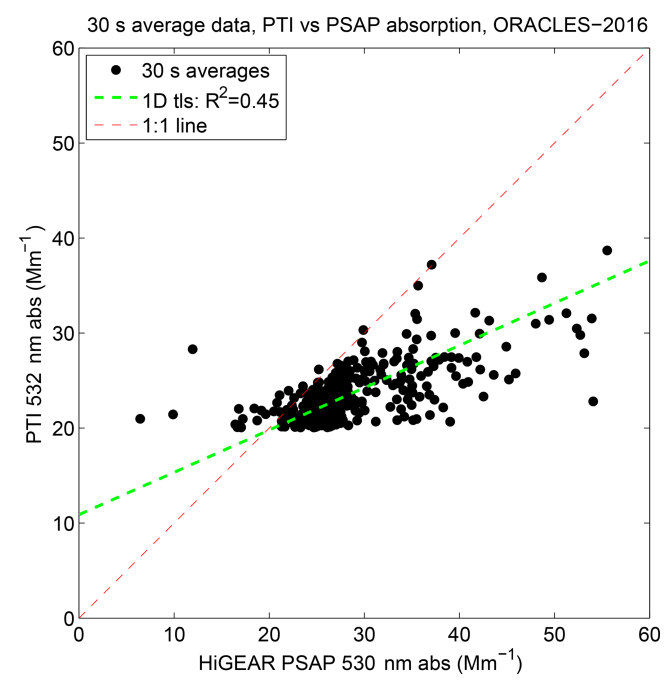

Figure A3. Comparison between PTI versus PSAP aerosol absorption coefficient (at 532 and $530 \mathrm{~nm}$, respectively) for all available flight data. Lines show a $1: 1$ relationship (red dashed) and a totalleast-squares fit (green dashed) through the data. The slope of the green line is 0.445 with an intercept of 10.9. There was no discernible distinction in the fits or correlations between the two instruments either between the in-plume leg and profile or by altitude. 
Author contributions. JR and PZ are PIs for the ORACLES campaign, with SD on the deployment leadership team and providing advisory expertise. SB and RF provided HSRL-2 data. BC, XL, SS, and BvD provided RSP data. SC and KSS provided SSFR data. KP, CF, MK, SL, and MSR provided 4STAR data. SF and SGH provided HiGEAR data. AJS provided PTI data. GVH and FX provided AirMSPI data. YS was the ORACLES data manager and created campaign merge datasets. KP performed the bulk of the comparative analysis and wrote the paper, both with input from the other authors.

Competing interests. The authors declare that they have no conflict of interest.

Special issue statement. This article is part of the special issue "New observations and related modelling studies of the aerosolcloud-climate system in the Southeast Atlantic and southern Africa regions (ACP/AMT inter-journal SI)". It is not associated with a conference.

Acknowledgements. We thank the ORACLES deployment support teams and the science team for a successful and productive mission. Part of this research was carried out at the Jet Propulsion Laboratory, California Institute of Technology, under a contract with the National Aeronautics and Space Administration (NASA).

Financial support. This research has been supported by the National Aeronautics and Space Administration Earth Venture Suborbital-2 program (grant no. NNH13ZDA001N-EVS2).

Review statement. This paper was edited by Joshua Schwarz and reviewed by two anonymous referees.

\section{References}

4STAR Team (LeBlanc, S., Flynn, C. J., Shinozuka, Y., SegalRozenhaimer, M., Pistone, K., Kacenelenbogen, M., Redemann, J., Schmid, B., Russell, P., Livingston, J., and Zhang, Q.): 4STAR_codes: 4STAR processing codes, Zenodo, https://doi.org/10.5281/zenodo.1492912, 2019.

Abel, S., Haywood, J., Highwood, E., Li, J., and Buseck, P.: Evolution of biomass burning aerosol properties from an agricultural fire in southern Africa, Geophys. Res. Lett., 30, 1783, https://doi.org/10.1029/2003GL017342, 2003.

Ackerman, A., Toon, O., Stevens, D., Heymsfield, A., Ramanathan, V., and Welton, E.: Reduction of tropical cloudiness by soot, Science, 288, 1042-1047, https://doi.org/10.1126/science.288.5468.1042, 2000.

Adebiyi, A. A. and Zuidema, P.: The role of the southern African easterly jet in modifying the southeast Atlantic aerosol and cloud environments, Q. J. Roy. Meteor. Soc., 142, 1574-1589, https://doi.org/10.1002/qj.2765, 2016.
Adebiyi, A. A. and Zuidema, P.: Low Cloud Cover Sensitivity to Biomass-Burning Aerosols and Meteorology over the Southeast Atlantic, J. Climate, 31, 4329-4346, https://doi.org/10.1175/JCLI-D-17-0406.1, 2018.

AirMSPI Science Team: AirMSPI ORACLES Cloud Droplet Size and Cloud Optical Depth, https://doi.org/10.5067/AIRCRAFT/ ORACLES/RADIANCE/AirMSPI, 2019.

Albrecht, B.: Aerosols, Cloud Microphysics, and Fractional Cloudiness, Science, 245, 1227-1230, https://doi.org/10.1126/science.245.4923.1227, 1989.

Anderson, T. and Ogren, J.: Determining aerosol radiative properties using the TSI 3563 integrating nephelometer, Aerosol Sci. Tech., 29, 57-69, https://doi.org/10.1080/02786829808965551, 1998.

Anderson, T., Masonis, S., Covert, D., Ahlquist, N., Howell, S., Clarke, A., and McNaughton, C.: Variability of aerosol optical properties derived from in situ aircraft measurements during ACE-Asia, J. Geophys. Res.-Atmos., 108, https://doi.org/10.1029/2002JD003247, 2003.

Arnott, W., Moosmuller, H., Sheridan, P., Ogren, J., Raspet, R., Slaton, W., Hand, J., Kreidenweis, S., and Collett, J.: Photoacoustic and filter-based ambient aerosol light absorption measurements: Instrument comparisons and the role of relative humidity, J. Geophys. Res.-Atmos., 108, AAC 15-1-AAC 15-11, https://doi.org/10.1029/2002JD002165, 2003.

Bahadur, R., Praveen, P. S., Xu, Y., and Ramanathan, V.: Solar absorption by elemental and brown carbon determined from spectral observations, P. Natl. Acad. Sci. USA, 109, 17366-17371, https://doi.org/10.1073/pnas.1205910109, 2012.

Bergstrom, R., Pilewskie, P., Schmid, B., and Russell, P.: Estimates of the spectral aerosol single scattering albedo and aerosol radiative effects during SAFARI 2000, J. Geophys. Res.-Atmos., 108, 8474, https://doi.org/10.1029/2002JD002435, 2003.

Bergstrom, R. W., Pilewskie, P., Russell, P. B., Redemann, J., Bond, T. C., Quinn, P. K., and Sierau, B.: Spectral absorption properties of atmospheric aerosols, Atmos. Chem. Phys., 7, 5937-5943, https://doi.org/10.5194/acp-7-5937-2007, 2007.

Bergstrom, R. W., Schmidt, K. S., Coddington, O., Pilewskie, P., Guan, H., Livingston, J. M., Redemann, J., and Russell, P. B.: Aerosol spectral absorption in the Mexico City area: results from airborne measurements during MILAGRO/INTEX B, Atmos. Chem. Phys., 10, 6333-6343, https://doi.org/10.5194/acp10-6333-2010, 2010.

Brem, B. T., Gonzalez, F. C. M., Meyers, S. R., Bond, T. C., and Rood, M. J.: Laboratory-Measured Optical Properties of Inorganic and Organic Aerosols at Relative Humidities up to 95\%, Aerosol Sci. Tech., 46, 178-190, https://doi.org/10.1080/02786826.2011.617794, 2012.

Brown, H., Liu, X., Feng, Y., Jiang, Y., Wu, M., Lu, Z., Wu, C., Murphy, S., and Pokhrel, R.: Radiative effect and climate impacts of brown carbon with the Community Atmosphere Model (CAM5), Atmos. Chem. Phys., 18, 17745-17768, https://doi.org/10.5194/acp-18-17745-2018, 2018.

Brown, S., Johnson, B., Biggar, S., Zalewski, E., Cooper, J., Hajek, P., Hildum, E., Grant, P., Barnes, R., and Butler, J.: Radiometric validation of NASA's Ames Research Center's Sensor Calibration Laboratory, Appl. Optics, 44, 6426-6443, https://doi.org/10.1364/AO.44.006426, 2005. 
Cairns, B., Russell, E., and Travis, L.: The research scanning polarimeter: Calibration and ground-based measurements, in: Polarization: Measurement, Analysis, and Remote Sensing II, edited by: Goldstein, D. H. and Chenault, D. B., Vol. 3754 of Proceedings of the Society of Photo-Optical Instrumentation Engineers (SPIE), 186-196, https://doi.org/10.1117/12.366329, Conference on Polarization - Measurement, Analysis, and Remote Sensing II, 19-21 July 1999, Denver, CO, 1999.

Chand, D., Anderson, T. L., Wood, R., Charlson, R. J., Hu, Y., Liu, Z., and Vaughan, M.: Quantifying above-cloud aerosol using spaceborne lidar for improved understanding of cloudy-sky direct climate forcing, J. Geophys. Res.-Atmos., 113, D13206, https://doi.org/10.1029/2007JD009433, 2008.

Chand, D., Wood, R., Anderson, T. L., Satheesh, S. K., and Charlson, R. J.: Satellite-derived direct radiative effect of aerosols dependent on cloud cover, Nat. Geosci., 2, 181-184, https://doi.org/10.1038/NGEO437, 2009.

Chylek, P. and Coakley, J.: Aerosols and Climate, Science, 183, 7577, 1974.

Cochrane, S. P., Schmidt, K. S., Chen, H., Pilewskie, P., Kittelman, S., Redemann, J., LeBlanc, S., Pistone, K., Kacenelenbogen, M., Segal Rozenhaimer, M., Shinozuka, Y., Flynn, C., Platnick, S., Meyer, K., Ferrare, R., Burton, S., Hostetler, C., Howell, S., Dobracki, A., and Doherty, S.: Above-Cloud Aerosol Radiative Effects based on ORACLES 2016 and ORACLES 2017 Aircraft Experiments, Atmos. Meas. Tech. Discuss., https://doi.org/10.5194/amt-2019-125, in review, 2019.

Diner, D. J., Xu, F., Garay, M. J., Martonchik, J. V., Rheingans, B. E., Geier, S., Davis, A., Hancock, B. R., Jovanovic, V. M., Bull, M. A., Capraro, K., Chipman, R. A., and McClain, S. C.: The Airborne Multiangle SpectroPolarimetric Imager (AirMSPI): a new tool for aerosol and cloud remote sensing, Atmos. Meas. Tech., 6, 2007-2025, https://doi.org/10.5194/amt-6-2007-2013, 2013

Dobracki, A., Freitag, S., Howell, S., Podolske, J., Redemann, J., Saide, P., Sedlacek, A., and Zuidema, P.: Total Organic Carbon Loss and Changes in Bulk Chemical Composition Seen in Vertically Stratified Aged African Biomass Burning Plumes over the Southeast Atlantic Ocean during ORACLES, in: American Meteorological Society Annual Meeting 2019, available at: https://ams.confex.com/ams/2019Annual/webprogram/ Paper352175.html (last access: 9 July 2019), 2019.

Dubovik, O. and King, M.: A flexible inversion algorithm for retrieval of aerosol optical properties from Sun and sky radiance measurements, J. Geophys. Res.-Atmos., 105, 20673-20696, https://doi.org/10.1029/2000JD900282, 2000.

Dubovik, O., Holben, B., Eck, T., Smirnov, A., Kaufman, Y., King, M., Tanre, D., and Slutsker, I.: Variability of absorption and optical properties of key aerosol types observed in worldwide locations, J. Atmos. Sci., 59, 590-608, https://doi.org/10.1175/15200469(2002)059<0590:VOAAOP>2.0.CO;2, 2002

Dunagan, S. E., Johnson, R., Zavaleta, J., Russell, P. B., Schmid, B., Flynn, C., Redemann, J., Shinozuka, Y., Livingston, J., and Segal-Rosenhaimer, M.: Spectrometer for Sky-Scanning Sun-Tracking Atmospheric Research (4STAR): Instrument Technology, Remote Sensing, 5, 3872-3895, https://doi.org/10.3390/rs5083872, 2013.

Eck, T., Holben, B., Ward, D., Mukelabai, M., Dubovik, O., Smirnov, A., Schafer, J., Hsu, N., Piketh, S., Queface, A.,
Le Roux, J., Swap, R., and Slutsker, I.: Variability of biomass burning aerosol optical characteristics in southern Africa during the SAFARI 2000 dry season campaign and a comparison of single scattering albedo estimates from radiometric measurements, J. Geophys. Res.-Atmos., 108, 8477, https://doi.org/10.1029/2002JD002321, 2003.

Eck, T. F., Holben, B. N., Reid, J. S., Mukelabai, M. M., Piketh, S. J., Torres, O., Jethva, H. T., Hyer, E. J., Ward, D. E., Dubovik, O., Sinyuk, A., Schafer, J. S., Giles, D. M., Sorokin, M., Smirnov, A., and Slutsker, I.: A seasonal trend of single scattering albedo in southern African biomass-burning particles: Implications for satellite products and estimates of emissions for the world's largest biomass-burning source, J. Geophys. Res.-Atmos., 118, 6414-6432, https://doi.org/10.1002/jgrd.50500, 2013.

Gordon, H., Field, P. R., Abel, S. J., Dalvi, M., Grosvenor, D. P., Hill, A. A., Johnson, B. T., Miltenberger, A. K., Yoshioka, M., and Carslaw, K. S.: Large simulated radiative effects of smoke in the south-east Atlantic, Atmos. Chem. Phys., 18, 15261-15289, https://doi.org/10.5194/acp-18-15261-2018, 2018.

Gyawali, M., Arnott, W. P., Lewis, K., and Moosmüller, H.: In situ aerosol optics in Reno, NV, USA during and after the summer 2008 California wildfires and the influence of absorbing and nonabsorbing organic coatings on spectral light absorption, Atmos. Chem. Phys., 9, 8007-8015, https://doi.org/10.5194/acp-9-80072009, 2009.

Haywood, J., Francis, P., Dubovik, O., Glew, M., and Holben, B.: Comparison of aerosol size distributions, radiative properties, and optical depths determined by aircraft observations and Sun photometers during SAFARI 2000, J. Geophys. Res.-Atmos., 108, 8471, https://doi.org/10.1029/2002JD002250, 2003.

Howell, S., Clarke, A., Shinozuka, Y., Kapustin, V., McNaughton, C., Huebert, B., Doherty, S., and Anderson, T.: Influence of relative humidity upon pollution and dust during ACE-Asia: Size distributions and implications for optical properties, J. Geophys. Res.-Atmos., 111, D06205, https://doi.org/10.1029/2004JD005759, 2006.

Jethva, H., Torres, O., Waquet, F., Chand, D., and Hu, Y.: How do A-train sensors intercompare in the retrieval of above-cloud aerosol optical depth? A case study-based assessment, Geophys. Res. Lett., 41, 186-192, https://doi.org/10.1002/2013GL058405, 2014.

Kacenelenbogen, M. S., Vaughan, M. A., Redemann, J., Young, S. A., Liu, Z., Hu, Y., Omar, A. H., LeBlanc, S., Shinozuka, Y., Livingston, J., Zhang, Q., and Powell, K. A.: Estimations of global shortwave direct aerosol radiative effects above opaque water clouds using a combination of A-Train satellite sensors, Atmos. Chem. Phys., 19, 4933-4962, https://doi.org/10.5194/acp19-4933-2019, 2019.

Knobelspiesse, K., Cairns, B., Redemann, J., Bergstrom, R. W., and Stohl, A.: Simultaneous retrieval of aerosol and cloud properties during the MILAGRO field campaign, Atmos. Chem. Phys., 11, 6245-6263, https://doi.org/10.5194/acp-11-6245-2011, 2011.

Koch, D. and Del Genio, A. D.: Black carbon semi-direct effects on cloud cover: review and synthesis, Atmos. Chem. Phys., 10, 7685-7696, https://doi.org/10.5194/acp-10-7685-2010, 2010.

Konovalov, I. B., Beekmann, M., Berezin, E. V., Formenti, P., and Andreae, M. O.: Probing into the aging dynamics of biomass burning aerosol by using satellite measurements of aerosol opti- 
cal depth and carbon monoxide, Atmos. Chem. Phys., 17, 45134537, https://doi.org/10.5194/acp-17-4513-2017, 2017.

Lack, D. A. and Cappa, C. D.: Impact of brown and clear carbon on light absorption enhancement, single scatter albedo and absorption wavelength dependence of black carbon, Atmos. Chem. Phys., 10, 4207-4220, https://doi.org/10.5194/acp10-4207-2010, 2010.

Lack, D. A., Cappa, C. D., Covert, D. S., Baynard, T., Massoli, P., Sierau, B., Bates, T. S., Quinn, P. K., Lovejoy, E. R., and Ravishankara, A. R.: Bias in filter-based aerosol light absorption measurements due to organic aerosol loading: Evidence from ambient measurements, Aerosol Sci. Tech., 42, 1033-1041, https://doi.org/10.1080/02786820802389277, 2008.

Langridge, J. M., Richardson, M. S., Lack, D., Law, D., and Murphy, D. M.: Aircraft Instrument for Comprehensive Characterization of Aerosol Optical Properties, Part I: Wavelength-Dependent Optical Extinction and Its Relative Humidity Dependence Measured Using Cavity Ringdown Spectroscopy, Aerosol Sci. Tech., 45, 1305-1318, https://doi.org/10.1080/02786826.2011.592745, 2011.

Leahy, L. V., Anderson, T. L., Eck, T. F., and Bergstrom, R. W.: A synthesis of single scattering albedo of biomass burning aerosol over southern Africa during SAFARI 2000, Geophys. Res. Lett., 34, https://doi.org/10.1029/2007GL029697, 2007.

LeBlanc, S. E., Redemann, J., Flynn, C., Pistone, K., Kacenelenbogen, M., Segal-Rosenheimer, M., Shinozuka, Y., Dunagan, S., Dahlgren, R. P., Meyer, K., Podolske, J., Howell, S. G., Freitag, S., Small-Griswold, J., Holben, B., Diamond, M., Formenti, P., Piketh, S., Maggs-Kölling, G., Gerber, M., and Namwoonde, A.: Above Cloud Aerosol Optical Depth from airborne observations in the South-East Atlantic, Atmos. Chem. Phys. Discuss., https://doi.org/10.5194/acp-2019-43, in review, 2019.

Lewis, K. A., Arnott, W. P., Moosmüller, H., Chakrabarty, R. K., Carrico, C. M., Kreidenweis, S. M., Day, D. E., Malm, W. C., Laskin, A., Jimenez, J. L., Ulbrich, I. M., Huffman, J. A., Onasch, T. B., Trimborn, A., Liu, L., and Mishchenko, M. I.: Reduction in biomass burning aerosol light absorption upon humidification: roles of inorganically-induced hygroscopicity, particle collapse, and photoacoustic heat and mass transfer, Atmos. Chem. Phys., 9, 8949-8966, https://doi.org/10.5194/acp-9-89492009, 2009.

Liu, S., Aiken, A. C., Arata, C., Dubey, M. K., Stockwell, C. E., Yokelson, R. J., Stone, E. A., Jayarathne, T., Robinson, A. L., DeMott, P. J., and Kreidenweis, S. M.: Aerosol single scattering albedo dependence on biomass combustion efficiency: Laboratory and field studies, Geophys. Res. Lett., 41, 742-748, https://doi.org/10.1002/2013GL058392, 2014.

Liu, Z., Winker, D., Omar, A., Vaughan, M., Kar, J., Trepte, C., $\mathrm{Hu}$, Y., and Schuster, G.: Evaluation of CALIOP $532 \mathrm{~nm}$ aerosol optical depth over opaque water clouds, Atmos. Chem. Phys., 15, 1265-1288, https://doi.org/10.5194/acp-15-1265-2015, 2015.

Liu, X., Stamnes, S., Burton, S., Ferrare, R., Hostetler, C., Hair, J. W., and Cairns, B.: A Combined Lidar and Polarimeter Optimal Estimation Algorithm for Aerosol Microphysical Property Retrievals, in preparation, 2019.

Lu, Z., Liu, X., Zhang, Z., Zhao, C., Meyer, K., Rajapakshe, C., Wu, C., Yang, Z., and Penner, J. E.: Biomass smoke from southern Africa can significantly enhance the brightness of stratocumulus over the southeastern Atlantic Ocean, P. Natl. Acad. Sci. USA,
115, 2924-2929, https://doi.org/10.1073/pnas.1713703115, 2018.

Magi, B. and Hobbs, P.: Effects of humidity on aerosols in southern Africa during the biomass burning season, J. Geophys. Res.-Atmos., 108, 8495, https://doi.org/10.1029/2002JD002144, 2003.

McComiskey, A. and Feingold, G.: The scale problem in quantifying aerosol indirect effects, Atmos. Chem. Phys., 12, 1031-1049, https://doi.org/10.5194/acp-12-1031-2012, 2012.

McNaughton, C. S., Clarke, A. D., Freitag, S., Kapustin, V. N., Kondo, Y., Moteki, N., Sahu, L., Takegawa, N., Schwarz, J. P., Spackman, J. R., Watts, L., Diskin, G., Podolske, J., Holloway, J. S., Wisthaler, A., Mikoviny, T., de Gouw, J., Warneke, C., Jimenez, J., Cubison, M., Howell, S. G., Middlebrook, A., Bahreini, R., Anderson, B. E., Winstead, E., Thornhill, K. L., Lack, D., Cozic, J., and Brock, C. A.: Absorbing aerosol in the troposphere of the Western Arctic during the 2008 ARCTAS/ARCPAC airborne field campaigns, Atmos. Chem. Phys., 11, 7561-7582, https://doi.org/10.5194/acp-117561-2011, 2011.

Meyer, K., Platnick, S., and Zhang, Z.: Simultaneously inferring above-cloud absorbing aerosol optical thickness and underlying liquid phase cloud optical and microphysical properties using MODIS, J. Geophys. Res.-Atmos., 120, 5524-5547, https://doi.org/10.1002/2015JD023128, 2015.

Mikhailov, E., Vlasenko, S., Podgorny, I., Ramanathan, V., and Corrigan, C.: Optical properties of soot-water drop agglomerates: An experimental study, J. Geophys. Res.-Atmos., 111, D07209, https://doi.org/10.1029/2005JD006389, 2006.

ORACLES Science Team: Suite of Aerosol, Cloud, and Related Data Acquired Aboard P3 During ORACLES 2016, Version 1, https://doi.org/10.5067/Suborbital/ORACLES/P3/2016_V1, 2019a.

ORACLES Science Team: Suite of Aerosol, Cloud, and Related Data Acquired Aboard ER2 During ORACLES 2016, Version 1, https://doi.org/10.5067/Suborbital/ORACLES/ER2/2016_V1, $2019 b$.

Pilewskie, P., Pommier, J., Bergstrom, R., Gore, W., Howard, S., Rabbette, M., Schmid, B., Hobbs, P., and Tsay, S.: Solar spectral radiative forcing during the Southern African Regional Science Initiative, J. Geophys. Res.-Atmos., 108, 8486, https://doi.org/10.1029/2002JD002411, 2003.

Pokhrel, R. P., Wagner, N. L., Langridge, J. M., Lack, D. A., Jayarathne, T., Stone, E. A., Stockwell, C. E., Yokelson, R. J., and Murphy, S. M.: Parameterization of single-scattering albedo (SSA) and absorption Ångström exponent (AAE) with EC/OC for aerosol emissions from biomass burning, Atmos. Chem. Phys., 16, 9549-9561, https://doi.org/10.5194/acp-169549-2016, 2016.

Quéfacé, A., Piketh, S., Annegarn, H., Holben, B., and Uthui, R.: Retrieval of aerosol optical thickness and size distribution from the CIMEL Sun photometer over Inhaca Island, Mozambique, J. Geophys. Res.-Atmos., 108, 8509, https://doi.org/10.1029/2002JD002374, 2003.

Redemann, J., Russell, P., and Hamill, P.: Dependence of aerosol light absorption and single-scattering albedo on ambient relative humidity for sulfate aerosols with black carbon cores, J. Geophys. Res.-Atmos., 106, 27485-27495, https://doi.org/10.1029/2001JD900231, 2001. 
Redemann, J., Flynn, C. J., Shinozuka, Y., Russell, P., Kacenelenbogen, M., Segal-Rosenhaimer, M., Livingston, J., Schmid, B., Dunagan, S., Johnson, R., LeBlanc, S., Schmidt, S., Pilewskie, P., and Song, S.: Aerosol properties derived from airborne sky radiance and direct beam measurements in recent NASA and DoE field campaigns, in: AGU 2014 Fall Meeting, San Francisco, CA, 2014.

Russell, P. B., Bergstrom, R. W., Shinozuka, Y., Clarke, A. D., DeCarlo, P. F., Jimenez, J. L., Livingston, J. M., Redemann, J., Dubovik, O., and Strawa, A.: Absorption Angstrom Exponent in AERONET and related data as an indicator of aerosol composition, Atmos. Chem. Phys., 10, 1155-1169, https://doi.org/10.5194/acp-10-1155-2010, 2010.

Sakaeda, N., Wood, R., and Rasch, P. J.: Direct and semidirect aerosol effects of southern African biomass burning aerosol, J. Geophysi. Res.-Atmos., 116, D12205, https://doi.org/10.1029/2010JD015540, 2011.

Sayer, A. M., Hsu, N. C., Eck, T. F., Smirnov, A., and Holben, B. N.: AERONET-based models of smoke-dominated aerosol near source regions and transported over oceans, and implications for satellite retrievals of aerosol optical depth, Atmos. Chem. Phys., 14, 11493-11523, https://doi.org/10.5194/acp-14-114932014, 2014.

Schafer, J. S., Eck, T. F., Holben, B. N., Thornhill, K. L., Anderson, B. E., Sinyuk, A., Giles, D. M., Winstead, E. L., Ziemba, L. D., Beyersdorf, A. J., Kenny, P. R., Smirnov, A., and Slutsker, I.: Intercomparison of aerosol single-scattering albedo derived from AERONET surface radiometers and LARGE in situ aircraft profiles during the 2011 DRAGON-MD and DISCOVERAQ experiments, J. Geophys. Res.-Atmos., 119, 7439-7452, https://doi.org/10.1002/2013JD021166, 2014.

Schmid, B., Redemann, J., Russell, P., Hobbs, P., Hlavka, D., McGill, M., Holben, B., Welton, E., Campbell, J., Torres, O., Kahn, R., Diner, D., Helmlinger, M., Chu, D., Robles-Gonzalez, C., and de Leeuw, G.: Coordinated airborne, spaceborne, and ground-based measurements of massive thick aerosol layers during the dry season in southern Africa, J. Geophys. Res.-Atmos., 108, 8496, https://doi.org/10.1029/2002JD002297, 2003.

Schmidt, K. S., Pilewskie, P., Bergstrom, R., Coddington, O., Redemann, J., Livingston, J., Russell, P., Bierwirth, E., Wendisch, M., Gore, W., Dubey, M. K., and Mazzoleni, C.: A new method for deriving aerosol solar radiative forcing and its first application within MILAGRO/INTEX-B, Atmos. Chem. Phys., 10, 78297843, https://doi.org/10.5194/acp-10-7829-2010, 2010.

Schmidt, S. and Pilewskie, P.: Airborne measurements of spectral shortwave radiation in cloud and aerosol remote sensing and energy budget studies, edited by: Kokhanovsky, A. A., 239-288, Springer Berlin Heidelberg, Berlin, Heidelberg, https://doi.org/10.1007/978-3-642-15531-4_6, 2012.

Schnaiter, M., Linke, C., Mohler, O., Naumann, K., Saathoff, H., Wagner, R., Schurath, U., and Wehner, B.: Absorption amplification of black carbon internally mixed with secondary organic aerosol, J. Geophys. Res.-Atmos., 110, D19204, https://doi.org/10.1029/2005JD006046, 2005.

Sedlacek, A.: Real-time detection of ambient aerosols using photothermal interferometry: Folded Jamin interferometer, Rev. Sci. Instrum., 77, 064903, https://doi.org/10.1063/1.2205623, 2006.
Sedlacek, A. and Lee, J.: Photothermal interferometric aerosol absorption spectrometry, Aerosol Sci. Tech., 41, 1089-1101, https://doi.org/10.1080/02786820701697812, 2007.

Segal-Rosenheimer, M., Russell, P. B., Schmid, B., Redemann, J., Livingston, J. M., Flynn, C. J., Johnson, R. R., Dunagan, S. E., Shinozuka, Y., Herman, J., Cede, A., Abuhassan, N., Comstock, J. M., Hubbe, J. M., Zelenyuk, A., and Wilson, J.: Tracking elevated pollution layers with a newly developed hyperspectral Sun/Sky spectrometer (4STAR): Results from the TCAP 2012 and 2013 campaigns, J. Geophys. Res.-Atmos., 119, 2611-2628, https://doi.org/10.1002/2013JD020884, 2014.

Segal-Rozenhaimer, M., Miller, D. J., Knobelspiesse, K., Redemann, J., Cairns, B., and Alexandrov, M. D.: Development of neural network retrievals of liquid cloud properties from multiangle polarimetric observations, J. Quant. Spectrosc. Ra., 220, 39-51, https://doi.org/10.1016/j.jqsrt.2018.08.030, 2018.

Shinozuka, Y., Johnson, R. R., Flynn, C. J., Russell, P. B., Schmid, B., Redemann, J., Dunagan, S. E., Kluzek, C. D., Hubbe, J. M., Segal-Rosenheimer, M., Livingston, J. M., Eck, T. F., Wagener, R., Gregory, L., Chand, D., Berg, L. K., Rogers, R. R., Ferrare, R. A., Hair, J. W., Hostetler, C. A., and Burton, S. P.: Hyperspectral aerosol optical depths from TCAP flights, J. Geophys. Res.-Atmos., 118, 12180-12194, https://doi.org/10.1002/2013JD020596, 2013.

Stamnes, S., Hostetler, C., Ferrare, R., Burton, S., Liu, X., Hair, J., Hu, Y., Wasilewski, A., Martin, W., van Diedenhoven, B., Chowdhary, J., Cetinic, I., Berg, L. K., Stamnes, K., and Cairns, B.: Simultaneous polarimeter retrievals of microphysical aerosol and ocean color parameters from the "MAPP" algorithm with comparison to high-spectral-resolution lidar aerosol and ocean products, Appl. Optics, 57, 2394-2413, https://doi.org/10.1364/AO.57.002394, 2018.

Swap, R., Annegarn, H., Suttles, J., King, M., Platnick, S., Privette, J., and Scholes, R.: Africa burning: A thematic analysis of the Southern African Regional Science Initiative (SAFARI 2000), J. Geophys. Res.-Atmos., 108, 8465, https://doi.org/10.1029/2003JD003747, 2003.

Torres, O., Jethva, H., and Bhartia, P. K.: Retrieval of Aerosol Optical Depth above Clouds from OMI Observations: Sensitivity Analysis and Case Studies, J. Atmos. Sci., 69, 1037-1053, https://doi.org/10.1175/JAS-D-11-0130.1, 2012.

Twomey, S.: Pollution and Planetary Albedo, Atmos. Environ., 8, 1251-1256, https://doi.org/10.1016/0004-6981(74)90004-3, 1974.

Vakkari, V., Kerminen, V.-M., Beukes, J. P., Tiitta, P., van Zyl, P. G., Josipovic, M., Venter, A. D., Jaars, K., Worsnop, D. R., Kulmala, M., and Laakso, L.: Rapid changes in biomass burning aerosols by atmospheric oxidation, Geophys. Res. Lett., 41, 2644-2651, https://doi.org/10.1002/2014GL059396, 2014.

Virkkula, A.: Correction of the Calibration of the 3-wavelength Particle Soot Absorption Photometer (3 PSAP), Aerosol Sci. Tech., 44, 706-712, https://doi.org/10.1080/02786826.2010.482110, 2010.

Wang, X., Heald, C. L., Sedlacek, A. J., de Sá, S. S., Martin, S. T., Alexander, M. L., Watson, T. B., Aiken, A. C., Springston, S. R., and Artaxo, P.: Deriving brown carbon from multiwavelength absorption measurements: method and application to AERONET and Aethalometer observations, Atmos. Chem. Phys., 16, 1273312752, https://doi.org/10.5194/acp-16-12733-2016, 2016. 
Waquet, F., Cornet, C., Deuzé, J.-L., Dubovik, O., Ducos, F., Goloub, P., Herman, M., Lapyonok, T., Labonnote, L. C., Riedi, J., Tanré, D., Thieuleux, F., and Vanbauce, C.: Retrieval of aerosol microphysical and optical properties above liquid clouds from POLDER/PARASOL polarization measurements, Atmos. Meas. Tech., 6, 991-1016, https://doi.org/10.5194/amt-6-9912013, 2013.

Wilcox, E. M.: Stratocumulus cloud thickening beneath layers of absorbing smoke aerosol, Atmos. Chem. Phys., 10, 1176911777, https://doi.org/10.5194/acp-10-11769-2010, 2010.

Wilcox, E. M.: Direct and semi-direct radiative forcing of smoke aerosols over clouds, Atmos. Chem. Phys., 12, 139-149, https://doi.org/10.5194/acp-12-139-2012, 2012.

Xu, F., van Harten, G., Diner, D. J., Davis, A. B., Seidel, F. C., Rheingans, B., Tosca, M., Alexandrov, M. D., Cairns, B., Ferrare, R. A., Burton, S. P., Fenn, M. A., Hostetler, C. A., Wood, R., and Redemann, J.: Coupled Retrieval of Liquid Water Cloud and Above-Cloud Aerosol Properties Using the Airborne Multiangle SpectroPolarimetric Imager (AirMSPI), J. Geophys. Res.-Atmos., 123, 3175-3204, https://doi.org/10.1002/2017JD027926, 2018.

$\mathrm{Xu}$, F., Diner., D., Dubovik, O., and Schechner, Y.: A correlated multi-pixel inversion approach for aerosol remote sensing, Remote Sensing, 11, 746, https://doi.org/10.3390/rs11070746, 2019.
Zhang, R., Khalizov, A. F., Pagels, J., Zhang, D., Xue, H., and McMurry, P. H.: Variability in morphology, hygroscopicity, and optical properties of soot aerosols during atmospheric processing, P. Natl. Acad. Sci. USA, 105, 10291-10296, https://doi.org/10.1073/pnas.0804860105, 2008.

Zhang, Z., Meyer, K., Yu, H., Platnick, S., Colarco, P., Liu, Z., and Oreopoulos, L.: Shortwave direct radiative effects of above-cloud aerosols over global oceans derived from 8 years of CALIOP and MODIS observations, Atmos. Chem. Phys., 16, 2877-2900, https://doi.org/10.5194/acp-16-2877-2016, 2016.

Zuidema, P., Redemann, J., Haywood, J., Wood, R., Piketh, S., Hipondoka, M., and Formenti, P.: Smoke and Clouds above the Southeast Atlantic Upcoming Field Campaigns Probe Absorbing Aerosol's Impact on Climate, B. Am. Meteorol. Soc., 97, 11311135, https://doi.org/10.1175/BAMS-D-15-00082.1, 2016.

Zuidema, P., Sedlacek, III, A. J., Flynn, C., Springston, S., Delgadillo, R., Zhang, J., Aiken, A. C., Koontz, A., and Muradyan, P.: The Ascension Island Boundary Layer in the Remote Southeast Atlantic is Often Smoky, Geophys. Res. Lett., 45, 44564465, https://doi.org/10.1002/2017GL076926, 2018. 